\title{
LA CULTURA POPULAR A CATALUNYA DELS SETANTES DEL SEGLE XX. UN ESBÓS D’ESTUDI²
}

A Catalunya, en el decurs dels setantes del s. XX es produeix una intensa galvanització i recomposició de la cultura popular. Hi emergeix, de fet, un nou marc de cultura popular. Aquest és indissociable d'unes noves concepcions de la cultura, l'art, la creativitat, la festa..., en tant que manifestacions eminentment populars. El període de màxima vitalitat d'aquesta nova (o intensament renovada) cultura popular correspon als darrers anys del Franquisme i als primers de la Transició i sobretot a aquests darrers. No cal dir que, més enllà, aquests són anys d'una intensa galvanització de la vida pública, pel que fa també a l'activitat política, a la vida sindical, al moviment veïnal, etc. Cal fer avinent, d'altra banda, que aquesta cultura popular és extremadament diversa. Podríem distingir-hi, amb tot, tres àmbits bàsics: l'acció sociocultural progressista, la promoció popular de la cultura catalana, i l'esfera underground.

Mots clau: Catalunya, cultura popular, galvanització i recomposició de la cultura popular, anys setantes, Tardofranquisme, Transició política, cultura catalana, acció sociocultural progressista, underground.

\section{La cultura popular, un concepte polièdric i controvertit}

El concepte de cultura popular s'ha emprat i s'empra amb sentits ben diversos. A partir sobretot del segle XX, aquest ha adquirit sentits diversos i àdhuc contradictoris. Des de la ciència i des d'altres camps se l'ha identificat i usat amb significacions diverses. Heus ací el perquè de la dificultat de llur fixació i el de la seva certa controvertibilitat. L'any 1981, els joves antropòlegs Dolors Llopart i Joan Prat deien "això que, tan

1 jcapdevila@filcat.udl.cat

2 Aquest article s'inscriu en el Projecte HAR2014-52882-P 
imprecisament encara, anomenem "cultura popular". ${ }^{3}$ Molt més ençà, el sociòleg D. Pasquier es referia a la dificultat d'abordatge d'aquesta categoria per part de les ciències socials:

"Pour les sciences sociales, le terme de «culture populaire» pose problème. Comment définir la culture populaire ? Par des acteurs sociaux? Par un type d'objets ou de contenus ? Faut-il la caractériser par opposition à d'autre formes culturelles? Mais dans ce cas, quelles sont les oppositions pertinentes? La variété des terminologies employées en dit long sur l'ambiguïté d'une telle tentative, même si elles renvoient toutes à l'idée d'une hiérarchie culturelle..." ${ }^{\prime 4}$

\subsection{Concepcions de la cultura popular}

A continuació mirem de definir els principals marcs de definició de "cultura popular" des del segle XIX fins a l'actualitat. Revisats els principals usos i definicions que se $n$ 'han fet, aquests serien els marcs bàsics de delimitació.

Una definició arrelada de cultura popular parteix de la seva identificació amb la cultura de les classes populars de l'antic règim; o més irrestrictivament amb la cultura de les classes populars de les societats preindustrials, amb la cultura del món pagès premodern; amb la cultura "tradicional" - o "popular i tradicional" - en definitiva: "Pour les historiens et les ethnologues, la référence au «populaire» passe la plupart du temps par l'étude de groupes socialement et géographiquement situés (...) d'études des cultures populaires villageoises". ${ }^{5}$

Coincideixen en aquest punt, entre altres, Gramsci, Bakhtin, Burke, Ginzburg, i Thompson, Així, Bakhtin, assaja, a partir de les novel·les cinccentistes de Rabelais, una interpretació de la cultura carnavalesca medieval i, a partir d'aquesta, de la cultura popular medieval, que contraposa a

3 Llopart, Dolors Joan Prat. La cultura popular a Catalunya: estudiosos i institucions: 1853-1981. Barcelona: Fundació Serveis de Cultura Popular i Ed. Alta Fulla, 1981. 149.

4 Pasquier, Dominique. "La «culture populaire» à l'épreuve des débats sociologiques". Hermès, la Revue, № 42, (2005/2): 60-69.

5 Pasquier, Dominique. "La «culture populaire» à l'épreuve des débats sociologiques"...": 61. 
les restriccions morals i expressives de la cultura oficial patrocinada pels estaments feudals. Burke, per la seva part, identifica la cultura popular amb la de les classes illetrades: una cultura configurada al voltant del cicle festiu anual, amb cançons, rondalles, teatre popular, imatgeria religiosa... Aquest historiador diferencia aquesta cultura de les cultures oficials (des de l'escolàstica a la II·lustració) i adverteix, però, que es produeixen intercanvis entre aquests estrats i que, fins al s. XVIII, les elits també participen de la cultura popular. D’altra banda, Ginzburg, a partir del cas d'un moliner friülès dels ss. XVI-XVII, posa en relleu que, entre sectors humils, hi subsisteix una cultura popular d'origen arcaic, més o menys autònoma, que mediatitza i integra en el seu univers de sentit altres fonts culturals i religioses. I altrament, Gramsci proposa ("filosofia de la praxi") l’assumpció per part de les classes humils d'una raó pràctica de matriu intel·lectual que els sigui útil per reflexionar sobre la pròpia condició històrica i per reformar -no per substituir- els seus costums i bastir una nova cultura i ètica col-lectives, en la perspectiva de la construcció d'un nou ordre material i un nou estat. ${ }^{6}$

D'altra banda, per exemple, en el si d'aquesta tradició interpretativa, el 1990, l'escriptor marroquí M. Khaïr-Eddine, en el pòrtic a l'edició de les actes d'un congrés d'etnologia del Marroc, reivindica la "culture populaire" del Magreb alhora que s'hi refereix, en un punt concret, com "des valeurs traditionelles et ancestralement bien établis."7 Situats en la nostra esfera cultural -també a tall d'exemple- unes concepcions i uns usos concurrents de cultura popular els tenim, uns anys abans, en La cultura popular a Catalunya (1981) que hem citat, i en el monogràfic de la revista mallorquina Lluc intitulat La nostra cultura popular (maig-juny de 1980).

Sense abandonar encara aquest marc interpretatiu, cal dir que el terme cultura popular també s'ha aplicat a la música folk. I s'ha emprat

6 Bakhtin, Mikhail. L'oeuvre de François Rabelais et la culturepopulaire au MoyenÂge et sous la Renaissance. Paris: Ed Gallimard, 1970. Burke, Peter. Popular Culture in Early Modern Europe. London: Temple Smith Ed., 1978. Ginzburg, C.. II formaggio e i vermi: ilcosmo di un mugnaio del' 500. Torino: G. Einaudi Ed.,1977. Gramsci, A. Quaderni del carcere. Torino: G. Einaudi Ed., 1975.

$7 \quad$ Hhaïr Eddine, Mohammed. "L'enracinement et l'universalité." La culture populaire: spécificités locales et dimension nationale. Rabat: Okad, 1990. 7-9. 
així mateix -des d'un prisma etnogràfic-a les formes de vida de les societats modernes i en particular urbanes, per bé que, quan aquestes esdevenen l'objecte únic d'atenció, l'enfocament emprat depassa aquesta tradició conceptual.

Una altra tradició de concepció de la cultura popular, prou definida, fa referència a la divulgació -en el sentit etimològic del terme- de la cultura; això és, a la seva extensió cap a les classes populars. En aquesta tradició, hom parteix de la noció de cultura que esdevé hegemònica al món occidental d'ençà la II·lustració: una cultura humanística, il·lustrada, racionalitzada; la concepció de cultura que resulta, en definitiva, àmpliament legítima fins als profunds canvis socials que a partir mitjan segle $X X$ afecten les societats occidentals; ${ }^{8}$ d'altra banda, en aquesta tradició hom es val d'un conjunt d'instruments que hom estima eficaços per a la culturització popular. Tenim, doncs, una tradició de concepció de la cultura popular com a "democratització" de la cultura.

Se situen en aquesta tradició de cultura popular, alguns tipus d'ateneus i de centres de sociabilitat fundats arreu d'Europa entre el segle XIX i les primeres dècades del segle XX. Es molt indicatiu en aquest sentit, pel seu caràcter històricament primerenc, el que disposa la "Introducción al informe de la Junta de Instrucción Pública" editat a Madrid el 1811 durant el regnat de José I quan l'ocupació napoleònica: “El autor de este Informe $(. . .)^{9}$ aprueba además el establecimiento de ateneos gracias a los cuales la masa, que no puede seguir la carrera de letras, no quedará del todo ignorante." ${ }^{10}$ D'altra banda, escauen paradigmàticament a aquesta tradició els "ateneus populars" adreçats expressament a l'educació cultural senso lato -científica, artística, moral...- dels sectors populars. Són casos

8 D’acord amb aquesta concepció de cultura, que parteix de la II·lustració, a aquesta hi corresponen el conjunt de sabers regits per la disciplina i el rigor racionals, intel-lectuals, per la depuració artística, i subjectes a unes tradicions específiques de què n'emanen uns cànons (i restriccions) específics.

9 Remet al informe de la Junta de Instrucción Pública publicat a Madrid el 12 d'octubre de 1810.

10 Mercader Riba, Joan. “Un aspecto de la cultura bajo el reinado de José Bonaparte: la Junta de Instrucción Pública y la idea de las Escuelas Normales y de los Ateneos". Homenaje al Dr. J. Juan Reglà Campistol. vol. II. València: Universitat de València. Facultat de Filosofia de Lletres, 1975. 261-264 
d'ateneus populars històrics el de l'Hospitalet de Llobregat, creat el 1932 amb els objectius de "millorament moral dels associats" i assoliment d' "un règim social més just" i amb el propòsit, amb aquestes fins, d'organitzar activitats formatives culturals, científiques, artístiques, professionals i físiques; ${ }^{11}$ i l'Ateneu Enciclopèdic Sempre Avant de Sants fundat el mateix any que el de la seva ciutat veïna. ${ }^{12}$ Amb una consideració concurrent de la cultura popular hi ha també els ateneus obrers com l'emblemàtic Ateneu Enciclopèdic Popular, que, amb una activitat important d'ençà meitat segle XIX, inicien un període de declivi a partir de la dècada dels anys deu per la profusió de manta entitats i mitjans adreçats a la formació cultural i tècnica. ${ }^{13}$

D’altra banda, institucions de la Diputació de Barcelona i de la Mancomunitat com l'Institut de Cultura i Biblioteca Popular de la Dona (1909) creat per a la formació cultural i professional de la dona, i sobretot de la treballadora, o les Biblioteques populars, obeeixen també a aquesta avaluació de la cultura popular. Com, altrament, també ho fa la revista El Amigo amb el subtítol de Revista Ilustrada de Cultura Popular, editada a Reus als anys vint del segle XX.

El franquisme també adapta i institucionalitza aquesta noció de cultura popular en el marc de de la Dirección General de Cultura Popular, molt present en la premsa de l'època. Altrament, en el marc de la Transició, a Catalunya, promoguda per Josep M. Vilaseca, és fundada la Fundació Serveis de Cultura Popular (1977), la qual, amb un ús intens i pioner del vídeo, malda per la capitalització cultural i científica de les classes populars, i sobretot dels sectors més desafavorits que provenen de l'emigració. ${ }^{14}$ Val a dir, finalment, que les "Jornades de Cultura Popular" que es fan en diver-

11 Marcè, Matilde. Ateneu de Cultura Popular de l'Hospitalet (1932-2007). L'Hospitalet de Llobregat: Ateneu de Cultura Popular, 2008. 22-23.

12 Montaner, Jordi. "Ayer y hoy de los ateneos populares. Resurge la vida cultural en los barrios barceloneses". La Vanguardia, Barcelona 28 de març de 1981, p. 66. .

13 Solà, Pere. Els ateneus obrers i la cultura popular a Catalunya (1900-1939): I'Ateneu Enciclopèdic Popular. Barcelona: La Magrana, 1978.

14 “(...) La idea havia pres força precisament aquell 1975. "La tasca es va orientar cap a lo popular poc a poc i baixant la part intel-lectual" anotava Vilaseca després d'una reunió de treball de la Fundació Pacis..." (Amat, Jordi. Un País a l'ombra: vida de Josep Maria Vilaseca Marcet (1919-1995). Barcelona: L’Avenç, 2015. 236). 
sos indrets durant la Transició i anys posteriors reflecteixen semblantment aquesta concepció de la cultura popular que ara hem esbossat.

Una altra concepció de cultura popular correspon -i ha correspost sobretot- a la que, en el marc d'un sistema de jerarquia cultural, es contraposa a la cultura legítima, identificada aquesta amb uns estrats de producció cultural proveïts d'uns nivells significatius de reeiximent intel·lectual o artístic i avaluats socialment com a cultura o art per antonomàsia. En la consagració d'aquesta cultura i en la concepció jerarquitzadora de la cultura que en resulta, hi intervenen, no cal dir-ho, un conjunt de sancions: la derivada d'una ideologia dominant de la cultura de matriu il.lustrada a què ens hem referit, la que resulta d'unes tradicions i cànons culturals i estètics institucionalitzats, i la que prové d'uns consums culturals socialment diferenciadors o conferidors de distinció. D'acord amb aquesta concepció cultural, que és essencialment la que Bourdieu planteja a La distinction (1979), un tractat que ha condicionat durant dècades la sociologia de la cultura a França allunyant-la dels Estudis Culturals en voga al món anglosaxó, la cultura de les classes populars es caracteritza per "le manque et la privation" i per la subalternitat doncs, de manera que els membres d'aquestes classes "sont condamnés à consommer des biens symboliques déclassés par ceux qui produisent les standards légitimes". ${ }^{15}$

Unes altres definicions de la cultura popular tenen a veure amb els gustos, consums, identificacions, interpretacions i pràctiques culturals característics de les classes populars o d'amplis estrats de la ciutadania en el decurs de les societats industrials i postindustrials, i amb la producció adreçada a la conformació i satisfacció d’aquests aspectes. Escauen, així, a aquestes definicions, productes com fulletons populars, novel·la i teatre "popular", imatgeria industrial de consum com postals, cromos, felicitacions, cartells, pòsters..., cançons i discs d'àmplia difusió, revistes divulgatives, films comercials i altres formes de narrativa audiovisual d'aquesta naturalesa, còmics, anuncis i espots publicitaris, etc. i també les formes de sociabilitat del lleure, de la festa i de la cultura de les classes populars, menestrals i de públics "democràtics", l'esport, grans espectacles massius, etc. Es tracta d'un univers -proteic a més no poder- de manifestacions; d'un marc d'exologiques"...: 60-69. 
pressions que determinen una progressiva substitució de les formes de cultura popular ancien régime o premoderna, i que en propicien, així mateix, una selectiva recreació en termes de cultura popular moderna.

Cal dir que en la conformació i desenvolupament d'aquesta cultura popular hi han tingut un paper fonamental els mecanismes bàsics de producció cultural de la modernitat: els marcs de sociabilitat de l'esbarjo, la festa i la cultura (cafès, casinos, ateneus, cabarets, sales de festa, discoteques...); les indústries culturals o els seus precedents (impremtes, editorials, discogràfiques, productores de cinema, d'esdeveniments...); els mitjans de comunicació; la publicitat; el disseny; i l'esport. Cal fer avinent, així mateix, que aquesta cultura ha esdevingut part essencial d'un ecosistema cultural complex i dinàmic (particularment dinàmic a partir mitjan $\mathrm{s}$. XX, i d'ençà d'altra banda la irrupció d'Internet) que ha tingut en la comunicació social ${ }^{16}$ i subsegüentment en la interacció amb l'esfera pública i en la seva (re)configuració, uns aspectes bàsics. D’altra banda, com ha estat remarcat per Bourdieu quant a la literatura de consum, un altra característica essencial n'ha estat l'heteronomia respecte als gustos dels públics a la recerca de la réussite économique. ${ }^{17}$

Quant als factors socials que han estat determinants en el desenvolupament d'aquesta moderna cultura popular i la cultura de masses en general, sens dubte que resulten pertinents els que referim tot seguit. En primer terme, la funció d'integració simbòlica que fan els seus productes respecte a l'esfera pública que aquests mateixos productes i els seus mitjans contribueixen tan essencialment a (re)definir. Aquesta funció i altres de concurrents exercides també característicament a partir de la recepció de productes d'aquest univers en l'esfera psicològica i fenomenològica com la catarsi de sentiments de frustració, d’anomia o d'ínfima autopresentació pública, han estat, en efecte, una circumstància facilitadora de primer ordre de la progressió d'aquestes cultures, i que explica també els termes com ho han fet. D’altra banda, un altre factor fonamental ha estat el desenvolupament de les noves tecnologies de la informació i la comunicació (amb Internet com a factor nuclear) i la crisi

16 A partir d'aquest tret, de la seva essencialitat, J.M. Tresserras i E. Marín van definir el conjunt d'aquest ecosistema cultural, com a "societat-cultura comunicació de masses" (Marín E. i Tresserras, J.M., Cultura de masses i postmodernitat: elogi i crítica de la comunicació contemporània. València: 3 i 4, 1984.).

17 Bourdieu, Pierre. "Le champ littéraire". Actes de la recherche en sciencies sociales, № 89, (1991): 4-46 i especialment 6-12 i 24-35. 
aguda de la cultura "il|lustrada", de la cultura fundada a partir de la II.lustració, i àdhuc de la formalitat i del sentit del mateix llenguatge, de la llengua que se n'havia performat i dotat de sentit. En tercer lloc, l'“erotització de la cultura" que s'esdevé a les societats occidentals a partir sobretot dels anys cinquanta i seixanta del s. XX, a conseqüència en primer terme de la conformació d'unes economies capitalistes excedentàries, que promouen i faciliten un consumisme totalment massificat, i dels processos resultants d'agudització anòmica que es produeixen especialment entre els joves atès que són els més sol-licitats per la nova acceleració i universalització consumista; i de manera que tot plegat, amb el concurs bàsic del disseny i la publicitat, propicia una profunda transformació de la cultura -entesa en un sentit ampli, de civilitzaciócaracteritzada per l'erotització, i de la qual la cultura pop i l'underground dels cinquantes-setantes en són les expressions potser més patents i per bé que només unes. I finalment, la conformació i desenvolupament d'aquestes darreres cultures i de les subcultures juvenils, amb franges de continuïtat entre si i límits sovint imprecisos, i que, com precisem en el següent apartat, suposen una nova lògica cultural, autònoma, autoreferencial, independent o refractària al tipus de jerarquitzacions culturals a què hem al-ludit, i que juguen un paper essencial en la definició d'unes noves identitats socials, amb l'element jove(nívol) com a tret central.

Les expressions d'aquest univers cultural han estat objecte d'estudi per part de la Teoria Crítica -especialment els media, avaluats com a indústries culturals- i ho han estat sobretot per part dels Cultural Studies. Aquests s'inicien a finals dels cinquantes al Regne Unit amb Raymond Williams, Richard Hoggart i E.P. Thompson com a referents principals i cristal-litzen amb el Center for Contemporany Cultural Studies de Birmingham. Poden destacar-se amb relació a aquests autors les indagacions de Thompson sobre formes de cultura popular (reunió, esbarjo, festa, espectacle, cançó, humor, etc.) de les classes populars de l'Anglaterra de les últimes dècades del XVIII i de les primeres del XIX que protagonitzen, a partir unes tradicions culturals prèvies, la industrialització i la primera urbanització moderna i la formació de la classe obrera; ${ }^{18}$ sobre literatura popu-

18 Thompson, E.P. The Making of the English Working Class. New York: Vintage Books. Randon House, 1966. Entre altres referències, quant a les transferències i recomposicions produïdes en la cultura popular durant la industrialització a Anglaterra a cavall del setcents i el vuitcents, resulta molt indicativa la que es fa a la p.59. 
lar de Williams i Hoggart; sobre ràdio d'aquest darrer; o sobre televisió i cinema de Williams, i també de Stuart Hall, que, a partir de 1968, dirigeix el referit centre fundat per Hoggart quatre anys abans. ${ }^{19}$

Des de la perspectiva dels Estudis Culturals, "les cultures populaires sont dotées d'un système de valeur et façonnent leur propre univers de sens." ${ }^{20}$ En concret, els fundadors d'aquest corrent i la tradició immediata que en resulta, malden per desentrellar les tradicions i perspectives culturals que resten incògnites darrere la cultura intel-lectual oficial anglesa. D’acord amb aquesta perspectiva teòrico-analítica, altrament a la passivitat alienadora que en destaca la Teoria Crítica, els receptors culturals són actius i creatius (Williams parla de "creative practice" respecte a la recepció cultural) ${ }^{21}$. Partint d'aquesta premissa, els estudis focalitzen la descodificació cultural, la significació atorgada pels receptors al producte cultural, la (re)interpretació que en fan, i això conscients que d'aquests actes poden derivar-se'n nous marcs de significació, noves preses de consciència o eixamplaments d'aquesta, noves formes de sociabilitat cultural o política, formes de resistència, etc., i benentès tot plegat, que, a tals efectes, es tenen en compte les estructures culturals prèvies.

A partir dels pares dels Estudis Culturals, aquests han evolucionat sensiblement quant a objectes i metodolologia. Poden ressaltar-se, així, les investigacions sobre subcultures juvenils dels anglesos D. Hebdige i P. Willis, i del l'americà P. Cohen. D’altra banda, si al Regne Unit, aquests estudis han prioritzat els productes populars i han tendit a una metodologia etnogràfica, als Estats Units han focalitzat els mitjans de comunicació i han propendit a obviar la separació entre cultura popular i cultura d'elit, i per bé que amb

19 Vegeu també: Willimams, Raymond. The Long revolution. Londres: Chato\&Windus, 1961. Williams, Raymond. Television:Technology and Cultural Form. New York: Schocken Books, 1975. Hoggart, Richard. The Uses of Literacy: aspects of working class life with special reference to publications and entertainments. Londes: Penguin Books, 1958. Hoggart, Richard i Janet Morgan (eds.). The Future of Broadcasting. Londres: MacMillan, 1982.. Hall, Stuart i Paddy Whannel. Popular Arts. A Critical Guide to the Mass Media. New York: Pantheon Books, 1965.

20 Pasquier, Dominique. "La «culture populaire» à l'épreuve des débats sociologiques"...: 62.

21 Beltrán, José. "Raymond Williams: perspectivas desde el materialismo cultural." M. Cometa, A. Lastra i P. Villar (eds.). Estudios culturales. Una introducción. Madrid: Verbum, 2007. 184-185. 
una propensió al populisme en reconcentrar-se en els mecanismes de resistència. I tot amb tot, actualment la sociologia de la cultura tendeix, d'acord amb la naturalesa de la complexificació social, a unes mirades més complexes que posen el focus en aspectes com les hibridacions entre formes culturals, les transferències culturals entre classes i grups socials, les formes de sociabilitat associades a la cultura, els impactes de la cultura de consum en el mercat social de les interaccions, etc.

Amb una concepció concurrent de cultura popular a la que acabem d'esbossar, Joaquim Molas, el 1982 i en relació principalment amb la literatura, s’hi referia com un ordre de produccions menys intel-lectualitzades i elaborades d'acord amb uns registres que les fan hàbils i atractives per a grans públics. ${ }^{22}$

D’altra banda, com és sabut, la cultura popular de consum massiu (o parts d'aquesta) ha estat sovint motiu de censura (intel-lectual sobretot) per tal com ha estat avaluada com a "sistèmica", "consumista", "alienant", etc. Situat en aquesta tradició de crítica cultural, el 1985, Antoni Tàpies, en un article important, ${ }^{23}$ censurava amb acritud la depauperació cultural i espiritual exercida per les "indústries culturals de profit" alhora que refusava emmarcar-ne llur producció en la dicotomia "alta i baixa cultura".

Un altre àmbit substantiu de la cultura contemporània és, sens dubte, l'underground. Amb aquest terme o el de contracultura, hom refereix aquelles expressions creatives i sociopolítiques, produïdes sobretot durant el període dels 50-70 del segle XX, que cerquen subvertir les regles artístiques i socials establertes. Aquest univers cultural, amb gran diversitat expressiva,

Molas, Joaquim. La Cultura catalana i la seva estratificació. Reflexions crítiques sobre la cultura catalana. Barcelona: Departament de cultura de la Generalitat de Catalunya, 1983.

23 “(...) I aclarim que entre aquests tipus d'indústries de la "cultura” actualment s'hi han de comptar no solament les que subministren productes que es consideren al gust vulgar (o mal gust) de les pobres masses desfavorides per la fortuna. També ho són molts dels negocis de pseudocultura, de cultura anestèsica o morta, als quals avui se'ls vol donar una aurèola intel-lectual i més refinada, promoguts tant pels mitjans impresos (textos anacrònics, novel-les rosa i de detectius, tebeos, enciclopèdies plenes de palla, pàgines i pàgines de revistes i diaris farcides de banalitats..) com pels mitjans anomenats electrònics (la fabulosa indústria d'instruments musicals i del disc, els "tinglados" de la televisió i del vídeo, tota la maquinària del cinema comercial..." (Tàpies, Antoni. "Per un art modern i progressista". La Vanguardia, Barcelona 15 de gener de 1985, p. 36). 
pot emmarcar-se, en molt bona mesura, en l'univers de l'allò popular. Dit això, resulta evident, tanmateix, que el seu àmbit pel que fa sobretot a algunes de les seves manifestacions com la música, se situa en un terreny híbrid o de frontera amb la cultura popular de consum massiu de què acabem de parlar. Moltes de les subcultures juvenils sobrevingudes a partir dels seixantes a partir de l'humus cultural del pop i de l'underground són un també altre àmbit bàsic de les cultures "populars" contemporànies.

\section{L'emergència de cultures populars al món occidental a partir meitat segle XX}

A partir meitat s. XX, primer als Estats Units i després al Regne Unit, es produeix l'eclosió d'unes noves cultures populars que suposen una autèntica revolució en relació amb les cultures populars en voga i a la tradició cultural occidental en general. Aquestes comporten, així mateix, una inflexió fonamental pel que fa a la internacionalització o globalització cultural. Ens referim principalment al "pop", l'underground i les subcultures juvenils.

La gènesi i el desenvolupament d'aquestes cultures no es poden entendre sense les transformacions de gran calat experimentades pels països occidentals a partir mitjan s. XX, quan s'hi produeixen uns períodes de fort creixement econòmic i de diferenciació social, d'intensificació i universalització del consumisme, de desenvolupament d'un nou ecosistema informatiu i comunicatiu afavorit per la creixent difusió i universalització del televisor i dels automòbils, i pels canvis potents en la publicitat i el disseny. Són un ordre de transformacions que comporten una complexificació de l'estructura social, unes percepcions en aquest ordre, i unes visions del "món" de marcat caràcter panoràmic. Tot plegat contribueix, així mateix, a uns fenòmens de densificació, facilitació i sensualització de la informació social. Aquests factors, fonamentals en l'evolució del món contemporani i especialment a partir d'aquesta època, es manifesten d'antuvi als EEUU per tal com no han patit directament la Segona Guerra Mundial, i, acabada aquesta, operen una reconversió accelerada de part de la seva hipertròfica indústria militar en indústria de béns civils.

Els joves es converteixen en els més sensibles envers alguns dels fenòmens acabats de referir. D'una banda, els imperatius evolutius de l'edat, 
que hi determinen una percepció especialment amatent i desperta cap al món, i envers allò nou, i d’altra banda, el fet d'ésser el segment més sol-licitat pel consumisme, poden explicar aquesta circumstància. Tot just aquesta -el fet que siguin els que més perceben la complexitat de la societat, el seu caràcter panoràmic, o que siguin els que més s'adonen de la concentració, l'accessibilitat i la sensualització de la informació- fa que siguin també els que experimentin més críticament la contradicció essencial que, en relació amb aquests fenòmens, suposa el manteniment d'estructures socials repressives o restrictives com la família tradicional, la moral tradicional, el sistema universitari, o la mateixa estructura de l'estat. Els joves universitaris, donada la jerarquització i l'anquilosament de la universitat dels seixantes o setantes, per la seva major intel·lectualització i predisposició a la percepció crítica i reflexió respecte del món, i per la seva condició de grup més cohesionat i amb una identitat més travada, són els que manifesten més agudament i estridentment aquests contrasentits. ${ }^{24}$

Aquestes contradiccions, les seves experiències per part sobretot de sectors de joves, comporten un procés massiu (el primer de gran abast en la història contemporània) de crisi de plausibilitat dels models de societat racional-estatistes desenvolupats a partir de l'estat modern. Introdueixen, així és, una crisi severa respecte de la racionalitat moderna i les formes institucionals (burocràtiques, jeràrquiques, constrictives vitalment) que s'hi funden, i compel-leixen al seu desbordament. Més en concret, aquestes contradiccions - i heus ací la lògica essencial d'aquestes desafeccions i d'aquests contestes- provoquen una incisiva intensificació social de l'anomia o de la manca de plausibilitat del jo respecte del món, ${ }^{25}$ i comporten al mateix temps, unes experiències i expressions de 'desrealització' o de pèrdua de força de realitat d'allò real.

D’altra banda, els fenòmens apuntats en primer lloc (l'embranzida del consumisme), les contradiccions que suposen respecte d'unes estructures percebudes $\mathrm{i}$ avaluades com a dissonants, $\mathrm{i}$ les experiències anòmiques que en resulten, propicien una nova consciència de la joventut com a classe; una nova consciència indeslligable poc o molt d'uns sentiments de plenitud

24 Capmany, Maria Aurèlia. La joventut és una nova classe?. Barcelona: Edicions 62, 1969. 171-211.

25 Quant al concepte d'anomia: Berger, Peter i Thomas Luckmann. La construcció social de la realitat. Barcelona: Herder, 1988. 129,141-164. 
vital i de consciència de tasca històrica. Més enllà, pot parlar-se d'una certa absolutització de la joventut com a etapa vital i com a valor, correlativa a una creixent comprehensivitat cronològica i desdelimitació d'aquesta i a una progressiva neutralització del seu caràcter de passatge evolutiu. ${ }^{26}$ També durant aquest període, de manera concurrent, emergeix amb força la categoria de "poble" i agafen força expressions ben diverses de popularisme.

Bé, doncs, aquestes serien, essencialment, les condicions d'eclosió d'un nou ordre de cultures populars de marcat caràcter juvenil. Les hem categoritzades com el pop, l'underground i les subcultures juvenils si bé podrien definir-se altrament. Aquestes cultures coincideixen -tot i que de maneres prou diverses- en una propensió a la transgressió (evident i estrident en l'underground i més domesticada i amable en el pop) i encara més en l'erotització. Tant és així que l'erotització o l'estetització de la rebel-lia n'esdevé un tret essencialment i diversament manifestat. Es tracta d'unes formes simbòliques que posen en relleu el malestar al qual hem al-ludit i que traeixen alhora (i paradoxalment si volem) el marc de consumisme en què s'arrelen. D'altra banda, les seves manifestacions esdevenen també uns eficaços correlats simbòlics de la joventut en tant que nova classe i nou valor. Volem adduir, finalment, que l'autoreferencialitat narcisista ${ }^{27}$ i la teatralització de les pròpies presentacions, són uns altres trets significatius d'aquestes cultures. ${ }^{28}$

Ja ens hem referit breument a l'underground. Els seus principals camps d'expressió artística i cultural són la música i el teatre. Quant a la primera, destaquen el folk i el rock (folk-rock, rock progressiu, jazz-rock, rock psico-

Tot just el 1968 John and Margaret Rowntree publiquen l'article "Youth as a class" a la revista àcrata Our Generation, editat després com a opuscle pel Southern Student Organizing Committee, un actiu grup de joves estudiants del sud dels EEUU situat en l'underground polític dels seixantes (Rowntree, John and Margaret. Youth as a class. London: Southern Student Organizing Committee, 1968). L'any següent, Maria Aurèlia Capmany, manllevant títol d'aquest treball i amb algunes reflexions inspirades pel mateix, publica l'assaig: La joventut és una nova classe? Quant a aquest aspecte, i amb relació a l'època que ens ocupa, vegeu les reflexions suggerents i no exemptes de controvèrsia de Lipovetsky en el seu classic L'Ere du vide (Lipovetsky, Gilles. La era del vacío. Ensayos sobre el individualismo contemporáneo. Barcelona: Anagrama, 1986. 12-15, 49-78).

28 Vegeu alguns apunts sobre la qüestió a Capdevila, Joaquim. "Modernidad tardía e hiperteatralidad. El performance en al vida social de cambio de siglos XX y XX." José L. Crespo Fajardo (coord.). Estudios sobre arte y comunicación social. La Laguna: Sociedad Latina de Comunicación Social, 2011. 41-52. 
dèlic, rock àcid, hard rock....). Pel que fa al teatre, Maffi diferencia entre l'experimental, el comunitari, el de guerrilla i el d'informació i debat. El seu període de major expressivitat, sobretot als Estats Units, correspon a la dècada dels seixantes. A finals d'aquesta dècada, aquest corrent emprèn (es fa especialment patent a Europa) un procés de radicalització i politització. ${ }^{29}$

D'altra banda, el pop es manifesta sobretot en l'esfera musical. En són trets característics melodies i lletres simples que busquen un fort atractiu popular i grans èxits massius, i una imperiosa lògica mercantil. Als seixanta (durant els seus inicis sobretot) és identificat amb el rock. Més endavant, assumint ascendències diverses, defineix un estil propi i esdevé determinant en la conformació de la música "disco" que triomfa als setantes i primers vuitantes.

Les fronteres entre el pop i el proteic univers underground no són nítides, i no ho són sobretot en el camp musical, fortament determinat per les indústries discogràfiques, els negocis de representació d'artistes, les cadenes de ràdio, etc. Es tracta d'uns poderosos condicionants que contribueixen a la potent mitogènesi que es produeix en aquesta esfera. ${ }^{30}$

L'emergència d'aquestes noves cultures suposa, d'altra banda, la crisi definitiva de la dicotomia entre cultura popular -sinònim d'escassa elaboració intel-lectual i adreçada a uns públics populars o democràticsi cultura legítima o cultura en majúscules, racionalitzada o artísticament depurada i adreçada a uns estrats ciutadans socialment distingits.

A Catalunya el marc conflictiu que hem esbossat, mediatitzat i extremitzat per la Dictadura, esdevé fonamental per a l'emergència d'uns nous marcs ideològics, culturals i identitaris, i amb relació amb aquests, per al desenvolupament des noves formes de cultura popular. Ho introduïm una mica més endavant.

29 Maffi, Mario. La cultura underground. Bari: Laterza, 1972. 26-40.

30 Es patent la integració mercantilitzadora i consumista de les grans figures de la música underground. Mecanismes industrials o mercantils com les grans discogràfiques, les productores d'esdeveniments, les emissores de ràdio comercial o reconeixements com els discos d'or contribueixen a aquesta integració sistèmica. Així -i només a tall de petit apunt- The Doors, que el 1966 guanya el disc d'or amb Light my fire, enregistra amb Elektra Records que el 1972 es fusiona amb Asylum Records; The Who, per la seva part, té contracte amb la important discogràfica Decca. 


\section{Catalunya i Espanya entre els darrers anys de la Dictadura i la Transició}

A partir dels anys 1969-70, es manifesten símptomes significatius de crisi del règim de Franco. ${ }^{31}$ Segons Ysàs, "el franquisme va entrar en una crisi cada vegada més oberta i aguda, producte certament d'una diversitat de factors, entre els quals destaca la conflictivitat social i política" promoguda per "un seguit de moviments -obrers, estudiantils, veïnals, cívics i culturals- impulsats per activistes antifranquistes".

Són anys d'intensificació de l'activitat política de l'oposició antifranquista. Així, per exemple, el 1969 es constitueix la Coordinadora de Forces Polítiques de Catalunya amb el PSUC, el MSC, FNC, UDC i ERC. D’altra banda, el 1971 es crea l'Assemblea de Catalunya, un instrument unitari que demostra la seva eficàcia fins a la primeria de la Transició. Aquest mateix any es funda el Bloc Popular de les Terres de Lleida, que assumeix una funció d'escola política en vistes a la Lleida posterior a la Dictadura. D’altra banda, el 1974 s'intensifica l'activitat que esdevé especialment forta fins als primers anys de la Transició. És indicatiu, així, que aquesta any es fundin Convergència Democràtica de Catalunya (el mateix any que Pujol, n'és el principal impulsor, compra, amb altres empresaris catalanistes, El Correo Catalán, el segon rotatiu més llegit a Catalunya), Convergència Socialista de Catalunya, el Reagrupament Socialista i Democràtic de Catalunya, el PSAN provisional, que el FNC faci el seu congrés...; o en el terreny sindical, que es constitueixi la Unió de Pagesos. I també és l’any de la reconstrucció del PSOE en el marc del Congrés de Suresnes que guanya l'anomenat sector renovador encapçalat per Felipe González.

I si això és així també ho és que, a partir 1971 i així que s’incrementa la conflictivitat política i social, el règim intensifica la repressió, els episodis més emblemàtics de la qual són les execucions de Puig Antich i dels

31 Pagès, Pelai. "La transició democràtica, història d'un temps d'incertesa." Pelai Pagès (dir.). La transició democràtica als Països Catalans. Història i memòria. València: Publicacions de la Universitat de València, 2005. 15-30. Ysàs, Pere. "L’antifranquisme i la crisi de la Dictadura." Pelai Pagès (dir.). La transició democràtica als Països Catalans. Història i memòria. València: Publicacions de la Universitat de València, 2005. 31-48. Lladonosa, Manel. "La Transició i els seus contexts". IXè Congrés de Convivència Cívica a la Ciutat "La Transició Democràtica a Lleida". Lleida 26-28 de març de 2015 (Text inèdit). 
militants del FRAP i ETA, les d'aquests darrers a tres mesos de la mort de Franco. La resposta repressiva no aconsegueix, però, desactivar i neutralitzar la dissidència, obtenint, altrament, resultats contradictoris de contenció d'una banda i de major i reactiva intensificació de l'altra.

El novembre de 1975 mor Franco. I tot i això, com és remarcat per Pagès, "la situació precisa en què es troba el país" “ no era gens clara per a propiciar el canvi" de manera que "entre el novembre de 1975 i el juny de 1977, quan varen tenir lloc les primeres eleccions democràtiques, el país va viure situacions de tensió i violència inusitada." En aquest sentit, cal tenir en compte l'equívoca orientació reformista del primer govern de la monarquia, el nomenament de Joan Carles, la continuïtat d'Arias Navarro, el rupturisme de l'oposició democràtica, la repressió policial de les manifestacions de l'Assembla de Catalunya del febrer del 76, la immolació policial de quatre treballadors a Vitòria el març d'aquest any, l' atemptat ultra a Montejurra els mes de maig d'aquest any. I cal tenir present, així mateix, que tot i l'orientació reformista del govern Suárez del juliol de 1976 i els seus passos cap a la democràcia, la situació és contradictòria per tal com aquests no menats per l'oposició antifranquista, l'oposició democràtica, sinó per un sector del règim que s'apressa a fer-se demòcrata, i de manera que, en coherència, la democratització es fa des de la reforma del règim i no des de processos de ruptura com s'havia esdevingut a Grècia o a Portugal.

Certament, la intensa mobilització opositora dels primers mesos de 1976 fan que Suárez i sectors afins vagin acceptant objectius que porten a una democratització formal de l'estat. I amb tot, és cert també que, per contra, el gruix de l'oposició antifranquista fa renúncies molt importants com la república o una consulta popular sobre el règim polític

Cal fer avinent finalment que l'avinença amb un canvi pactat amb sectors provinents del règim per part de les principals forces de l'oposició al franquisme i la seva progressiva implantació, provoquen desencís i frustració en sectors de l'esquerra més radical i en l'independentisme. La violència política de Terra Lliure (1979) i l'agitació rupturista del MDT (1984) en són una prova. 


\section{Les cultures populars a Catalunya entre el Tardofranquisme i la Transició}

D’acord amb el creixement econòmic i la modernització dels països occidentals esdevinguda entre els cinquanta i primers setantes del s. XX, la societat catalana i espanyola de la dècada dels seixantes i de la primeria dels setantes experimenten un cert procés concurrent. Són anys, així, en què es produeixen increments rellevants del consum(isme), una certa internacionalització de la vida cultural i social, uns augments de la complexitat social, de la seva percepció, i de la percepció de la panoramicitat del món. I tot plegat es produeix alhora que perduren la Dictadura i unes estructures institucionals i socials de marcat caràcter constrictiu i àdhuc repressiu. Es tracta, d'altra banda, d'un ordre de circumstàncies viscudes especialment (i massivament) en l'esfera dels joves, i, pel que fa a l'Estat espanyol, afrontades especialment a Barcelona i a Catalunya atès el caràcter més obert i dinàmic de les seves societats i per la realitat nacional que les concerneix.

Ja hem parlat de la contradicció essencial que suposen els canvis socials i cognitius derivats de l'anomenada Golden Age of Capitalism respecte de les estructures culturals i socials socialment restrictives $i$ jeràrquiques provinents de les primeres societats industrials i fins i tot de societats de transició cap a aquestes. En el cas català i espanyol, l'existència d'una (llarga) Dictadura amplifica aquestes contradiccions, que també són aguditzades, d'altra banda, per les poderoses expectatives de canvi dels darrers anys del Franquisme i els primers de la Transició, i altrament, per les accions contradictòries del règim d'intentar desactivar o domesticar la lògica del canvi, i també per la crisi econòmica sobrevinguda poc abans del final del règim i que s'allargassa durant tota la Transició.

Al fil del que hem apuntat en el segon apartat, d'aquests processos i contradiccions se'n sobrevé, amb una especial incidència entre els joves, un ordre de fenòmens socials i polítics bàsics: una agudització de l'anomia, una complexificació de les identitats socials associada a l'emergència de noves o renovades identitats i a la crisi d'altres (la de la nació moderna, per exemple, que inicia un fonamental procés de crisi quant a la seva plausibilitat) i una radicalització política i cultural. 
Amb aquest marc general, a la Catalunya de l'últim Franquisme i de la Transició s'hi intensifica la cultura popular en general i s'hi desenvolupen unes noves cultures populars. Tot plegat es produeix en relació amb diversos marcs o cosmovisions ideològics, culturals i identitaris. Serien bàsicament els següents: a) un catalanisme nacional esquerranista, marxista; 32 b) un esquerranisme, marxisme, afecte a cert catalanisme cultural; c) un nou independentisme que apunta ja al postnacionalisme; ${ }^{33}$ i d) la contracultura, l'underground.

Una de les evidències de la intensificació i diversificació de la cultura popular durant aquesta etapa que tractem és la proliferació del terme "popular" amb relació a "cultura" o activitats culturals. En efecte, en el curs d'aquests anys trobem força iniciatives que remeten, a partir de les seves designacions o intencions a concepcions de cultura popular. Tenim, així, per exemple, les Festes Populars de Cultura Pompeu Fabra (1969-1993), el Primer Festival Popular de Poesia Catalana (1970), la "Temporada Popular" del Grec de l'estiu del 76 organitzada per l'Assemblea de Directors i Actors de Barcelona, els Consells Populars de Cultura Catalana (1977), l'empresa Enllaç "promotora de cultura popular", la Fundació Serveis de la Cultura Popular (1977), etc. O tenim, així mateix, els "ateneus populars" que es reprenen o es funden durant aquests anys, o les tantes "jornades de cultura popular" que se celebren durant aquest període històric.

Resulta també indicatiu, en aquest sentit, la reivindicació com a "arte popular" que fa Jordi Coca de les titelles amb ocasió del IV Festival Internacional de Titelles de Barcelona de $1977 .{ }^{34} \mathrm{O}$ ho és també la

32 Quant a aquesta cosmovisió, vegi's les referències que hi fa Casassas (Casassas, Jordi. El Noucentisme: assaig de revisió de les seves circumstàncies històriques. Barcelona: IEC, 2015. 7-8, 33).

33 Vegi's, per exemple, Capdevila, Joaquim. "Pòrtic." Lladonosa, Mariona. La construcció de la catalanitat. Evolució de la concepció d'identitat a Catalunya (18601990). Lleida: Universitat de Lleida, 2013. 7-22; i Capdevila, Joaquim, Lladonosa, Mariona i Soto, Joana. "Catalanism in the 1960s and 1970s. Late modernity and elements of intellectual, cultural and symbolic renovation". Langue et Littérature. Repères identitaires en contexte européen. Selected Papers of the 11th International Conference of The Faculty of Letters. Pitesti, 13-15 June 2014. Pitesti: Universitatea din Pitesti, 2014. 319-332.

34 A. M. M. "Presentación del libro: "Les grans tradicions populars: ombres i titelles". La Vanguardia, Barcelona 14 de maig de 1977, p. 59 
referència de "les sis hores de cançó popular" amb què el cronista d'El Diario de Lérida es refereix a la prohibició de les Sis Hores de Cançó a Bellpuig del 75, o la qualificació de "amplia expresión popular" amb la qual el cronista de La Vanguardia informa de les ara autoritzades "Sis Hores de Cançó" que se celebren a Bellpuig el 4 setembre de $1976 .{ }^{35}$ D'altra banda també és pertinent en aquest sentit el fet que "El Congreso de Cultura Catalana [iniciat el 1975] dará a la expresión cultura su más amplía definición (...) En el plano general, informado por la dimensión popular que, desde el principio, se ha amparado del Congreso..."36

I també són evidències de concepcions populars de la cultura els esdeveniments artístics i culturals de clara voluntat democratitzadora. Poden adduir-se, així, les celebracions artístiques fetes al carrer i les emblematitzacions d'aquesta circumstància: així, els espectacles "La poesia al carrer" de Celdoni Fonoll; o també, tot i no correspondre ja a la Transició, la "Fira del Teatre al Carrer" de Tàrrega iniciada el 1981 i el vídeo commemoratiu dels seus vint-i-cinc anys es titulà indicativament: Tots al carrer!, posen encara de manifest l'esperit popularitzador de la cultura dels anys previs. ${ }^{37}$

Certament, els sentits i les pràctiques que s'intriquen en la cultura popular d'aquests anys són heterogenis a més no poder. Hi trobem una gran diversitat d'expressions concretes (festivals i jornades musicals, artístiques; ateneus populars, casals de joves, premsa...); una gran heterogeneïtat de gèneres artístics i culturals (poesia, (para)teatre, pintura, còmic, cançó, rock, conferències...), i una gran varietat d'estils o de corrents estètico-ideològics (folk, rock, contracultura, cultura catalana). I amb tot, en aquesta gran diversitat, $\mathrm{s}^{\prime}$ hi evidencien uns principis que coincideixen en uns sentits de la cultura com a manifestació eminentment popular.

Mirem tot seguit d'assajar una definició de les cultures populars que es manifesten amb caràcter emergent a la Catalunya dels darrers anys del

35 "Con las suspensiones en Lérida, muy cerca del centenar". Diario de Lérida, Lleida 13 d'agost de 1975, p. 3. "Las "Sis hores de cançó», en Bellpuig". La Vanguardia, 2 de setembre de 1976, p. 28.

36 "El Congreso de Cultura Catalana". La Vanguardia, 8 d'agost de 1975, p. 21. "Congreso de Cultura Catalana". ABC, 7 d'agost de 1975, p. 23.

37 Giribet, Josep. Tots al carrer!: Tàrrega 1981. Barcelona i Tàrrega: Televisió de Catalunya, Bausan Films, Calidos, 2005. [enregistrament videogràfic] 
Franquisme i la Transició. Val a dir que aquestes, poc o molt, ja han adquirit aquesta condició amb anterioritat, i cal precisar sobretot que no es tracta d'unes cultures escindides, sinó que tot altrament es manifesten amb encreuaments de sentits i pràctiques.

Una esfera pròpia en aquest sentit correspon a la democratització de la cultura; escau, així és, a les iniciatives la lògica primordial de fer accessible la cultura (en tant que coneixement o experiència formativa) a les classes populars o a uns públics amplis. Institucions com els ateneus populars o ateneus amb una vocació en aquest sentit, jornades de "cultura popular", etc. són algunes de les manifestacions indicatives d'aquesta cultura que cerca, en darrer terme, el millorament o la transformació de la realitat social, de la general i particularment de la que li és més afí.

Un altre àmbit amb entitat pròpia és el de la promoció popular de la cultura catalana. Així és, durant aquests anys també es desenvolupa un marc diferenciable d'actuació orientat a la promoció popular de la cultura catalana; un marc adreçat a la seva promoció popular i alhora que al realçament de la gent, de les classes populars, de les viles, dels barris, en la mesura que es reapropien de cultura popular catalana, que la fan seva. Són molt diverses les expressions relatives a aquest àmbit: poden destacar-se la Nova Cançó i el sardanisme (ciutats pubilles, colles), les recuperades i recreades festes de Sant Joan i la Flama del Canigó, l'eclosió -en el decurs de la Transició i els anys immediatament posteriors- de revistes locals i altres iniciatives encaminades a la recuperació de la cultura i la identitat locals, les Festes Populars Pompeu Fabra, o el Congrés de Cultura Catalana i els Consells Populars de Cultura Catalana.

Un altre àmbit bàsic en la recomposició de la cultura popular a la Catalunya dels setantes i d'anys anteriors és el món de les expressions alternatives i underground. Com hem dit, les manifestacions que nodreixen aquesta esfera es caracteritzen per la dissidència amb relació als models artístics, culturals i socials establerts. L'exploració i l'experimentació (atrevida, arriscada, radical àdhuc) amb els llenguatges i els missatges creatius, és un tret tant bàsic com comú pel que fa a aquesta esfera proteica i dinàmica de manifestacions. La música (el folk, folk-rock, rock progressiu, "música laietana") i el teatre (teatre de carrer, comunitari, d'animació i de titelles; el teatre independent i experimental; el teatre d'informació i denúncia; el teatre de guerrilla) són els camps primordials de l'underground artístic a Catalunya. 
Situats en el període que tractem, el període de màxima vitalitat de la cultura popular correspon als últims anys del Franquisme i als primers de la Transició (fins al 77/78). Vegem-ne algunes dades reveladores. Les Sis Hores de Cançó Canet se celebren entre el 1971 i el 1978, el Canet Rock entre el 1975 i el 1978, les Sis Hores de Cançó a Bellpuig s'intenten celebrar o se celebren entre el 75 i el 77, la Setmana de Música Viva entre el 77 i el 79, el "Nadal al soterrani" (al metro de Barcelona) entre el 1977 i el 1978, i el Grec "autogestionat" per actors, directors i altres professionals, el 1976 i el 1977 (el 78 no se celebra i el del 79 té una gestió plenament municipalitzada).

A partir del 79 i encara més a partir del 1980 i 1981 es fa palès un retrocés quant a la vitalitat -pel que fa a la generativitat- de la cultura popular, en la seva diversitat. ¿Què ha passat? Quins factors coincideixen en aquest fet? Entre el 77 i el 82 comença a institucionalitzar-se un règim polític, i amb aquest, un nou sistema de partits i uns nous líders polítics. Amb aquest procés, progressivament, s'imposen els càlculs dels partits amb vocació de poder i els d'una nova classe política i, conforme a una lògica inversa, s'inicia la desactivació dels actors polítics, socials i culturals més emergents. D'altra banda, les noves institucions (els ajuntaments amb un rol central) es converteixen en programadors culturals amb la consegüent lògica institucionalitzadora de la cultura. I amb tot, val a dir, que molts dels primers ajuntaments democràtics (vegi's la Mercè o la Santa Tecla del 79) tendeixen a programar el ventall de cultura popular que s'havia manifestat de manera emergent els anys anteriors.

\section{Trets transversals en les cultures populars emergents a la Catalunya dels setantes}

Vegem, tot seguit, algunes de les concepcions que regeixen transversalment la cultura popular d'aquests anys. És quelcom que pot inferir-se a partir de l'anàlisi de les formes de les iniciatives portades a terme, i de l'anàlisi lingüística i del discurs amb què es presenten.

Un d'aquests trets transversals és el protagonisme que hi té el jovent. L'expressió artística i cultural es converteixen en factors de primer ordre d'afirmació generacional i empoderament de la joventut. És 
clar que aquesta circumstància no pot dissociar-se de la forta consciència generacional $^{38} \mathrm{i}$ àdhuc com a classe o estament a part que adquireix la joventut a partir dels seixantes. ${ }^{39}$

Vegem què es diu en aquest sentit en l'àlbum Folk-Song (1967), un dels primers del folk català:

"Fa uns quants anys, a Nord-Amèrica, va començar a revitalitzar-se la cançó popular, fent-la servir com a mitjà d'expressió de tot allò que la joventut volia dir.(...) En fer aquesta selecció [de folk americà], hem tingut en compte, no solament la gran importància que té que els joves cantin, i per a aquesta fi, renovar llur repertori, sinó també que aquestes cançons diguin alguna cosa" 40

Efectivament, els joves tenen un protagonisme primordial en l'embranzida artística i cultural d'aquests anys: "Érem joves i tot estava per fer,.....tot havia de ser possible!" diu Alfred Fort amb relació al paper del jovent en la dinamització cultural i popular de la Tarragona de la Transició. ${ }^{41}$ D'acord amb això, trobem que els joves, organitzats en associacions juvenils i també com a responsables d'entitats molt diverses que no són juvenils, són els actors principals de la dinamització cultural en general, i pel que fa sobretot a les esferes de la cultura popular i la contracultura.

Vegem-ne alguns exemples. Darrere el Centre d'Iniciatives i Turisme (CIT) de Granollers que organitza el primer festival de rock progressiu de l'Estat espanyol el 1971 així com altres iniciatives sonades a cavall de les acaballes del Franquisme i la primeria de la Transició, hi ha Joan Illa i altres joves amics seus d'aquesta ciutat vallesana.

Tenim, així mateix, que els organitzadors nominals de les primeres edicions de les Sis Hores de Cançó són escoltes de Canet, que en el Con-

38 Andy Furlong, especialista en sociologia escolar i de la joventut, diu que "generational consciousness is when a group of people become mindful of their place in a distinct group identifiable by their shared interests and values" (Furlong, Andy. Youth Studies: An Introduction. New York: Routledge, 2013. 12). Aquest tipus de consciència esdevé patent - bé que diversament- respecte a la joventut d'aquests anys.

39 Capmany, Maria Aurèlia. "La joventut és una nova classe?...": 171-211.

40 Folk-Song, Barcelona: Hogar del Libro, 1967.

41 Fort, Alfred. "Érem joves i tot estava per fer". Fet a Tarragona, Tarragona 23 de setembre de 2013. (Dossier central amb motiu de les Festes de Santa Tecla). 
grés de Cultura Catalana a l'Alt Empordà hi tenen un paper molt actiu els escoltes de la comarca, que el Grup de Joves de Bellpuig és l'organitzador de les Sis Hores de Cançó que se celebren en aquesta vila el setembre de 1976 i l'agost de 1977,42 que el "jovent de Calaf" és el promotor del "recital de Cançó Catalana celebrat a les pistes del Casal, i el dia 21 del mes d'agost" de 1976, ${ }^{43}$ que mesos abans, el febrer de 1976, es constitueix l'Agrupació de Joves de Mollerussa que setmanes després organitza un concert de cançó catalana en aquesta localitat, ${ }^{44}$ o que és I'Assemblea de Joves de Cervera la que promou l'Aquelarre en aquesta vila el 1978. ${ }^{45}$

Un altra característica transversal bàsica és la concepció de la cultura, l'expressió artística o la festa com a instruments d'afirmació i empoderament populars, i de transformació social. Resulta il.lustratiu en aquest sentit el lema de les temporades del 76 i 77 del Teatre Grec: "Per un teatre al servei del poble". N'és també d'indicatiu el lema "Cançons per al poble" $\mathrm{i}$ "Cançons del poble". Els trobem en els cicles "Terra viva, cançons per al poble" i "Cançons del poble" coordinats per Enllaç $(1974,1977) ; 46$ en el festival "Nit de la cançó per al poble", festival de cançó catalana

42 “El festival de Bellpuig no autorizado". Diario de Lérida, Lleida 1 d'agost 1975, p. 1. Benet, Carlos. "Sobre la no celebración de "Les sis-hores de Cançó a Bellpuig". Diario de Lérida, Lleida 2 d'agost 1975, p. 5. J.C. "Parcialitat simptomàtica. Suprimides 6 hores de música carta blanca a 12 hores de tenis" Diario de Lérida, Lleida 13 d’agost de 1975, p.3. "Las "Sis hores de cançó», en Bellpuig". La Vanguardia, 2 de setembre de 1976, p. 28.

43 "Comunicat del Jovent de Calaf". Revista de la Família Igualadina, núm. 1161, Igualada 9 de setembre de 1976, p. 7.

44 "Y hablando de dicha agrupación [de jóvenes] diremos que empezó sus actividades con un recital de canción catalana ofrecido el pasado sábado a las 10 de la noche en el que actuó Jorge Oró, la joven Telma, Miguel Sanxo, Miguel Tena, José Borrell con el seudónimo de "Xerric" con su acompañante Carlos Yuste y Eusebio Pascúal. con el seudónimo "Plauti" como humorista. (Mollerussa". Diario de Lérida, Lleida 15 de febrer de 1976, p. 8.).

45 Assemblea de Joves. "Primer Aquelarre al Carreró de les Bruixes". Carreró de les Bruixes, núm.3, Cervera "Extra Setembre [Festa Major de 1978]", p. 4.

46 "Recital de "cançó catalana» en Castellterçol". La Vanguardia, Barcelona 22 de de juliol de 1974, p. 52. La Vanguardia, Barcelona 11 d'agost de 1974, p. 45. La Vanguardia, Barcelona 13 d’agost de 1974, p.39. "EL ESPECTÁCULO Y LA MÚSICA EN CATALUÑA. La entidad "Enllaç» organiza numerosas actividades". La Vanguardia, Barcelona 22 de gener de 1977, p. 24. 
que se celebra a Selva (Mallorca) el 7 de juliol del $76 .{ }^{47} \mathrm{O}$ n'és així mateix el nom del grup d'art contracultural "Grup d'Art al Poble" creat a meitat dels setantes i integrat per Joan Barceló, Emili Flotats, Odina Martí.... Més enllà de la cultura, també revela aquesta voluntat d'empoderament popular la campanya de "Dinamització" del 1977, que té com a eslògan "vers un control popular del poder".

Unes actuacions especialment orientades a l'autoreivindicació, autocelebració i autoidentificació del poble -en el acostumats sentits progressistes d'aquests anys - tenen a veure amb la recuperació del carrer i de l'espai comunitari en general. Fort, jove tarragoní a qui ja ens hem referit, diu respecte als grups culturals de la Tarragona del moment: "L'any 79 és l'any! La sensació de llibertat esperona tots aquests col-lectius i aquell any ho podem considerar el punt de partida dels processos de recuperació i ocupació dels carrer..." ${ }^{48}$ Són també reveladors en aquest sentit les lluites i els treballs de reconversió en centres de cultura i esbarjo d'espais en desús. Només pel que fa a Barcelona tenim els casos de l'Ateneu Popular de Nou Barris que recupera una fàbrica abandonada, el de l'Ateneu Popular del Clot que ho fa de l'antiga farinera modernista del barri, de I'Ateneu Popular del Poblenou que ho fa respecte de la vella cooperativa La Flor de Maig, o tenim els casos de les mobilitzacions per convertir l'antic Mercat de la Flor (on s'hi edificarà el Teatre Lliure) en l'Ateneu Popular del Poble Sec, o per adequar l'abandonat mercat del Born en un ateneu o centre cultural per al casc antic de la ciutat.

Una altra de les lògiques més comunes en la cultura popular d'aquest període és l'autoorganització o l'autogestió per part de la mateixa gent destinatària o dels mateixos artistes. Aquest tret es manifesta sobretot en l'underground cultural: en el moviment hippie, orientalista, contracultural; i en l'extrema esquerra: anarquista, trostkista, marxista-leninista, en pro d'un socialisme autogestionari. En aquests entorns s'hi produeix una forta refractarietat cap a les estructures autoritàries i jeràrquiques esta-

47 La Vanguardia, Barcelona 18 de juliol de 1976, p. 47. “Autorizado en Mallorca el recital "Nit de Cançó per al Poble". La Vanguardia, Barcelona 31 de juliol de 1976, p. 34. “MALLORCA: Los pueblos de España estuvieron representados en la «Nit de la cançó per al poble". La Vanguardia, Barcelona 10 d'agost de de 1976, p. 8. Fort, Alfred. "Erem joves i tot estava per fer...". 
blertes. En l'underground cultural, aquesta desafecció afecta àdhuc les estructures cognitives i culturals més bàsiques de la societat immediata. Més enllà d'aquests àmbits i amb connexions tanmateix amb els mateixos, l'autogestió o l'autoorganització esdevé també característica del moviment juvenil i universitari d'aquesta època. En donen fe les moltes "assemblees", "grups" o "casals" de joves que apareixen. D’altra banda, l'esclat d'associacions culturals i veïnals que es verifica també en aquests moments, confirma també aquesta tendència.

M. Aurèlia Capmany, en el seu assaig La joventut és una nova classe? (1969), té un capítol intitulat "L'autogestió". ${ }^{49}$ Capmany hi exposa que les finalitats de la joventut universitària occidental són l'“autogestió dins la Universitat, veu i vot en qüestions polítiques i socials". Una mica abans i amb relació amb aquesta mateixa qüestió, apunta:

(...) el fet nou, que em sembla important de destacar, és la necessitat d'autogestió que es desperta en les élites escolars, a partir de la dècada dels cinquanta, com a conseqüència d'una presa de consciència com un refús a ser manipulats, dirigits, per un sistema que no respon a la seva pròpia finalitat. (...)

En la base de la nova situació conflictiva hi ha la denúncia de l'estructura universitària, una voluntat de cogestió que no és més que un punt de partida, la finalitat del qual és la democratització de la Universitat. ${ }^{50}$

Tingui's en compte, d'altra banda, que durant els seixantes i els setantes sobretot, a l'Europa occidental i als EEUU principalment, les reflexions i les propostes entorn de l'autogestió obrera i popular en general tenen una important repercussió en una part significativa de l'esquerra política, sindical i social. Els plantejaments (re)sorgits en aquest ordre són d'una gran heterogeneïtat. La naturalesa dels moviments de dissidència juvenil i cultural de què hem parlat, els dubtes i les desafeccions quant al model socialista soviètic i l'emmirallament en la via iugoslava, són factors que contribueixen a posicionaments favorables a idees i models d'autogestió o cogestió social en general. Quant als corrents que es manifesten en aquest sentit, poden reportar-se, a nivell internacional, l'anarquisme,

49 Capmany, Maria Aurèlia. "La joventut és una nova classe?..": 183-189.

50 Capmany, Maria Aurèlia. "La joventut és una nova classe?...": 175. 
el socialisme llibertari, el trotskisme, el consellisme, el situacionisme, i en un terreny més eclèctic, la new left o la francesa deuxième gauche.

A Catalunya, les formulacions favorables a l'autogestió o cogestió socialista cristal-litzen de manera rellevant en el decurs dels setantes de manera que són adoptades d'una manera o altra per part de les principals forces de l'esquerra. En dóna fe, per exemple, el llibre La Autogestión a debate editat el 1976 a Barcelona. Si la seva primera part assaja una aproximació a les concepcions i debats sobre l'autogestió, els seus models i sobre la seva aplicació, tot incidint en els seus vessants polític, econòmic, social i fins i tot cultural i personal, a la segona part, són dirigents de les organitzacions més destacades de l'esquerra catalana els que exposen com, des de les respectives formacions, s'entén i s'assumeix l'autogestió socialista en tant que via democràtica alternativa al capitalisme i independent del comunisme soviètic. Ho exposen, així, entre altres, Joan Raventós (PSC), Joan Cornudella (FNC), J. Solé Tura (PSUC) i també Enric Nosàs per part del RSDC i Miquel Roca per part de CDC. ${ }^{51}$

Quant a l'esfera cultural, ja hem dit que l'autoorganització o l'autogestió on més radicalment i nítidament s'expressen és en el terreny alternatiu i underground. En són mostres l'Assemblea d'Actors, Directors i Professionals que té cura del Teatre Lliure els anys 76-77, la productora artística Enllaç en què hi treballa Xesco Boix entre altres, el "Sindicat Musical de Catalunya" que organitza la Setmana de Música Viva i que reactiva l'Ateneu Colón per tal d'oferir actuacions en directe a Barcelona, i ho veiem en tantes i tantes agrupacions assembleàries, comunitàries i informals d'artistes d'aquests anys.

Aquesta filosofia de l'art i la cultura queda ben traïda en l'article "Col-lectivisme artístic" que Marcel-lí Corominas publica a la primeria del setanta-cinc:

(...) D'acord, però: qui pot negar que avui no es tendeix cap a un socialisme o col·lectivisme de l'expressió artística?

(...)La meva conscient creença que l'única expressió artística socialment vàlida per mostrar a la societat noves fites i el dret als seus drets, és la que neix d'un treball col·lectiu sense "vedettes" ni diferències.

51 La Autogestión a debate: fuerzas políticas y sindicales se interrogan sobre el tema. Barcelona: 7X7 Edicions, 1976. 
Proposo a qui ho vulgui, reviure els cafetins de la bohèmia, les velles tertúlies, per tal d'unir grups per a un treball conscient i conscienciador. Cal aconseguir la fita d'una igualtat social amb l'oblit de les arcaiques classes..." 52

D’altra banda, l'autoorganització cultural s'expressa a través de l'associacionisme local (veïnal, cultural, folklòric) que fa una intensa funció de dinamització social durant aquest període. Les associacions de veïns que pugnen perquè hi hagi ateneus populars al Born, Poblenou, Nou Barris, Clot o Poble Sec són exponents d'aquesta concepció organitzativa, com en són, quan aquestes lluites són reeixides, els ateneus en qüestió. D’altra banda, i a tall d'exemple concret, l'autoorganització és el factor de les "50 Hores d'Art Català" de Balaguer del març de 1975 en què hi intervenen, d'una banda, l'Ateneu de Balaguer, l'Orfeó de Balaguer, la llibreria La Noguera i els Amics de l'ONU d'aquesta població, i de l'altra, el col·lectiu contracultural 2 quarts de 10.

En la cultura popular d'aquests anys també esdevé comuna llur concepció com a vehicle d'identificació, cohesió i empoderament local (de barri, vila, poble). "Volem el Casc Antic per al Poble: Born Ateneu Popular" fa una pancarta exhibida en una de les activitats dutes a terme el tercer cap de setmana de gener del 77 per demanar la conversió de l'antic mercat del Born en un centre de cultura popular per als barris del casc antic de Barcelona. Als mateixos dies, la coordinadora Enllaç, en tant que col·laboradora del IV Festival de Titelles del setanta-set, afirma que "en contacto con asociaciones de vecinos y los grupos representativos de comarcas, intentará encontrar la propia esencia de cada barrio de Barcelona y de cada población de Cataluña". ${ }^{53}$ Un any i mig més tard, en la Setmana de la Música Viva que es fa a Barcelona se celebren "conciertos gratuitos en catorce barrios dando así a la música toda una auténtica proyección popular." ${ }^{44}$ Mesos més tard, com a extensió dels treballs de l'àmbit de

52 Coromines, Marcel-lí. "igualtat artística." 2 quarts de 10. La mare dels ous. Barcelona: Edicions 62, 1975. 19.

53 “EL ESPECTÁCULO Y LA MÚSICA EN CATALUÑA La entidad «Enllaç» organiza numerosas actividades". La Vanguardia, Barcelona 22 de gener de 1977, p. 24.

54 "La Semana de Música Viva, diseminada por todos los barrios de Barcelona y concentrada en el campo de deportes del club Europa". La Vanguardia, Barcelona 13 de juny de 1978, p. 62. 
cinema del Congrés de Cultura Catalana, se celebra la Setmana als Barris, "una de las actividades paralelas que extiende la programación a la casi totalidad de los barrios de nuestra ciudad a través de las asociaciones de vecinos". ${ }^{55}$ Es tracta, doncs, d'iniciatives diverses que posen tanmateix en relleu una voluntat de compromís i empoderament dels barris de la capital catalana quan els primers anys de la Transició.

Val a dir, finalment, que uns altres trets àmpliament rellevants de les cultures populars d'aquest període són la catalanitat per bé que concebuda molt diversament, la festa i la (para)teatralitat, i les concepcions de l'art i la cultura i al servei de la transformació social.

\section{Expressions emergents de cultura popular}

\subsection{La democratització de la cultura. La cultura com a acció sociocultural progressista}

Ja hem dit que una expressió clarament emergent de la cultura popular dels anys que abordem és la democratització de la cultura (entesa com a coneixement o experiència formativa) al servei sobretot dels sectors populars.

La Fundació Serveis de Cultura Popular (1977) és representativa d'aquesta orientació. Com diu Modest Reixach, "el qualificatiu "popular" de la seva denominació expressa més aviat l'interès de la Fundació pels havers i pels dèficits culturals de les capes més àmplies -popularsde la societat catalana". ${ }^{56}$ Un repàs de la seva actuació posa en relleu una atenció primordial per barris desafavorits, i permet constatar que ha actuat eventualment en col·laboració amb altres entitats educatives, culturals i socials. Un altre tret d'aquesta entitat ha estat un ús intens i pioner del vídeo didàctic amb produccions que han versat sobre totes els camps de la ciència. Val a dir, així mateix, que aquesta entitat ha editat també vídeos divulgatius sobre cultura popular catalana, història de Catalunya,

55 "XX Setmana internacional de Cinema de Barcelona". La Vanguardia, Barcelona 10 d'octubre de 1978, p. 58.

56 Reixach, Modest. "Fundació Serveis de Cultura Popular". Revista d'Etnologia de Catalunya, № 8, (1996): 109-110. 
barris de l'àrea metropolitana barcelonina, i en relació amb la immigració castellanoparlant arribada a Catalunya: Cinquanta-quatre relats d'immigració (1981) compilats per Jaume Botey.

Tenim, d'altra banda, el cas de Xarxa Cultural, empresa fundada també el 1977, l'objectiu primordial de la qual és contribuir a la normalització de la cultura catalana. Segons resa el seu manifest fundacional, el seu “campo de acción preferido serán las barriadas, las comarcas y los sectores sociales más carentes de instrumentos de formación, recreativos, y análogos". La seva oferta anuncia "edicions, discos, ceràmica, artesania popular, etc.", i preveu, a més, una interessant possibilitat d'integració a tot aquell qui d'alguna forma pertanyi a l'expressió "els altres catalans"'". ${ }^{57}$ També, d'altra banda, el programa "La Caixa a les escoles" recorre a aquest terreny d'actuació. Es així que el juny de 1974 agraeix "la col·laboració d'un gran nombre de professionals de diversos camps culturals que han aportat el seu treball i que en molts casos han hagut d'explicar i adaptar el seu treball a un públic infantil". ${ }^{58}$

En un altre ordre organitzatiu, uns altres instruments que corresponen a aquest enfocament cultural són els ateneus populars, amb aquest nom o amb aquesta vocació. Durant la Transició, però amb precedents en els anys previs, es produeix la creació, la reactivació i la reobertura de força ateneus (ateneus populars, sovint), alguns dels quals assoleixen una notorietat remarcable. ${ }^{59}$ I també es produeixen intents deseixits en aquest sentit. Es tracta d'ateneus ubicats a Barcelona i a la seva àrea directa d'influència, i d'ateneus en ciutats i pobles de la resta de Catalunya. En alguns casos, la lluita per la creació d'ateneus populars és indissociable del creixement precipitat dels barris i dels dèficits subsegüents en ordres diversos, i de la lluita veïnal impulsada sovint per militants antifranquistes. ${ }^{60}$

57 “Una cultura de peaje". La Vanguardia, Barcelona 1 d'abril de 1977, p. 23. Maluquer, Jordi. "Pre-política. Convocatòries abstractes". L'Avui, Barcelona 31 de març de 1977, p. 2.

58 .La Vanguardia, Barcelona 21 de juny de 1974, p. 14.

59 Aisa, Ferran (2006). “Els ateneus, una alternativa cultural fallida.” Aracil, Rafael, Mayayo, Andreu i Antoni Segura (eds.). Memòria de la Transició a Espanya i a Catalunya. Volum VI-VII. Barcelona: Centre d'Història Internacional.

60 Ysàs, Pere. "L'antifranquisme i la crisi de la Dictadura...": 36. 
Pel que fa als ateneus de Barcelona i de la seva àrea metropolitana, cal destacar la lluita, sostinguda entre el 19751977 sobretot, a favor de la conversió de l'antic (i abandonat) Mercat del Born en un ateneu popular o centre cultural per al casc antic de Barcelona; ${ }^{61}$ la creació, el gener del 77, de l'Ateneu Popular de Nou Barris després que uns dos-cents veïns hagin ocupat una fàbrica en desús i hagin maldat perquè s'hi comencin a fer, de manera autogestionada, activitats culturals diverses; ${ }^{.62}$ la fundació, aquest mateix any, de l'Ateneu Enciclopèdic Sempre Avant de Sants que restableix de fet l'activitat del ja creat el 1932; la constitució el desembre de 1978 de l'Ateneu La Flor de Maig del Poblenou que, emplaçat en l'antiga cooperativa homònima, culmina la lluita de la Coordinadora d'Entitats del Barri i de la Associació de Veïns a favor d'aquesta entitat, la qual passa a regir-se segons una doble finalitat: I' acollida d'entitats del barri sense seu i la creació de seccions pròpies d'oci cívico-cultural; ${ }^{63}$ la reobertura el mateix any de l'Ateneu Popular de l'Hospitalet fundat ja el 1932, que es proposa organitzar conferències sobre temes culturals i educatius, promoure cursos per millorar els coneixements en ciències i arts, obrir sales de lectura, organitzar exposicions, i en general, fer possibles totes aquelles activitats que acostin la cultura als seus associats; ${ }^{64}$ la ubicació provisional la primavera 1979 de l'Ateneu Popular del Clot en una antiga farinera modernista del barri després de mobilitzacions iniciades per l'Associació de Veïns el 1977. I cal fer constar, així mateix, el frustrat projecte

61 Vegi's, per exemple, el cartell "Salvem el Born per al poble" de 1975 amb una foto d'A. Ramis que figura l'interior del recinte. "Un patronazgo gestionará la utilización del Borne. En tanto no se decida su destino definitivo". La Vanguardia, Barcelona 9 de gener de 1977, p. 30. La Vanguardia, Barcelona 18 de gener de 1977, p. 40. Puig de la Bellacasa, José M. “Primera fase para la restauración del Born: 50 millones para renovar la infraestructura. Diálogo entre el Ayuntamientoy los vecinos. Se formará una comisión que elaborará el proyecto definitivo. Un Ateneo Popular, idea base". La Vanguardia, Barcelona 3 de febrer de 1977, p. 19.

62 "Aniversario de un equipamiento sociocultural. Más que pan y circo". El Periódico, Barcelona 10 de març de 2012..

63 Montaner, Jordi. "Ayer y hoy de los ateneos populares. Resurge la vida cultural en los barrios barceloneses". La Vanguardia, Barcelona 28 de març de 1981, p. 66. "Los locales de la antigua cooperativa «La Flor de Maig» serán Ateneo Popular". La Vanguardia, Barcelona 22 de maig de 1977, p. 24.

64 Marcè, Matilde. “Ateneu de Cultura Popular de l'Hospitalet (1932-2007)...": 48-51. 
de constituir l'Ateneu Popular del Poble Sec al Mercat de les Flors, a favor del qual, el maig de 1977, la Coordinadora de Joves del barri organitza un "Festival de música jove". 65

També en altres llocs de Catalunya es creen ateneus populars quan la Transició i els anys immediatament posteriors. Així -i només a tall d'exemple- poden adduir-se els casos de l'Ateneu Popular d'Hostalric que ja funciona el maig de 1975;66 I'Ateneu Popular de Ponent (1979) a Lleida, I'Ateneu Popular de la Fuliola (1979) o l'Ateneu Intercomarcal Mascançà, vinculat a Ràdio Ponent i creat, tanmateix, ja durant els primers vuitantes.

També hi ha ateneus històrics o de fundació més recent que, en aquest context dels darrers anys de la Dictadura i els de la Transició, adopten un model d'acció catalanista i popular o renoven i intensifiquen aquest plantejament. Dos casos indicatius d'això són l'Ateneu de Sant Just Desvern (1918) que, amb una llarga tradició catalanista, promou una potent activitat de divulgació catalana i popular a finals del Franquisme; i l'Ateneu de Balaguer (1966), que es catalanitza pocs anys després de la seva fundació i que promou una variada i àdhuc ambiciosa activitat cultural, molt remarcable pel que fa al cine-fòrum i el cine-club, i que inclou cançó catalana, obres de teatre, exposicions, cursos de sardanes, d'anglès, de francès, de guitarra, de fotografia... esdevenint un punt de trobada de l'antifranquisme a Balaguer. ${ }^{67}$

Un altre tipus d'ateneus que participen activament en la renovació i dinamització de la cultura popular, són els ateneus llibertaris, de què se'n produeix una eclosió a partir de $1977 .{ }^{68}$ Des d'Ajoblanco, Francesc Boldú, responsable aleshores de la secretaria de formació i cultura de la CNT, els

65 “«Festival de Música Jove», organizado por la Coordinadora de Jóvenes de Poble Sec. Forma parte de la campaña para la transformación del Mercado Central de Flores en Ateneo Popular...." ("«Festival de Música Jove», organizado por la Coordinadora de Jóvenes de Poble Sec". La Vanguardia, Barcelona 23 de març de 1977, p. 24).

66 La Vanguardia, Barcelona 11 de maig de 1975, p. 37.

67 L'Ateneu de Balaguer (1966-1978) també organitza segles homenatges a Pompeu Fabra i Pau Casals, i s'hi clausura l'àmbit d'història del Congrés de Cultura Catalana. (Solanes, Marc. "Cinquanta anys de l'Ateneu de Balaguer" (http://www. balaguer.tv/cinquanta-anys-de-lateneu-de-balaguer/)

68 Mínguez, Luis. "Algomás que "pasotas", vida y cultura, humanizar el barrio. Ateneos libertarios". Triunfo, Madrid 11 de novembre de 1978, p. 44-45 
defineix com "un espacio propicio para la cultura. Para la cultura libertaria. Para una transformación del barrio. Como un túrmix de imaginación y colectividad que transformará tu barrio/pueblo. Ya antes lo fue...". ${ }^{69}$ Quan les Jornades Llibertàries del juliol del 77 a Barcelona, els seus cartells indiquen que les entrades poden ser adquirides en ateneus Ilibertaris. Pel que fa a aquests centres, destaquen l'Ateneu Llibertari de Sants (el primer de tots, creat el setembre de 1976), Gràcia (al carrer Perill), Poble Sec, Sant Andreu, o Rubí.

Un altre model d'ateneu -singular però indicatiu del moment- és I'Ateneu Colón del Poblenou en ser assumit, el juny de 1980, pel Sindicat Musical de Catalunya (que agrupa músics catalans de tots els estils) per fer-hi música en directe. ${ }^{70}$

Quant a altres centres de promoció popular de la cultura, cal fer referència a les cases o centres de cultura, de què se'n produeix també una creació remarcable durant aquest període i anys concurrents. A tall indicatiu, reportem aquests casos: la Casa de Cultura de Juneda (1975) creada a partir de la donació del metge Josep Cornudella; la Fundació Mauri (1969) de La Garriga fundada a partir de la donació de Jaume Mauri; el Casal de Cultura Dr. Daurella (1975) de Cardedeu fundat arran d'una deixa de Santiago Daurella a l'Ajuntament de la vila; i el Casal de Cultura Robert Brillas (1972) d'Esplugues de Llobregat.

D’altra banda, aquests anys, també molts mitjans de comunicació local (premsa i ràdio) fan una important funció d'empoderament i d'identificació de la gent, del seu comú, respecte dels respectius llocs; i això tenint en compte que aquests són anys fecunds pel que fa a iniciatives de comunicació local.

Una iniciativa molt interessant en aquest sentit és el Noticiari de Barcelona (1977-1980), sorgit com informatiu cinematogràfic quinzenal de Barcelona i els seus barris, que es fa en català, i que s'endega a fi de substituir el NODO. Aquest noticiari, amb una informació concorde amb una mentalitat més pròxima a l'espectador, es projecta als cinemes de

69 Boldú Martínez, Francesc. "Ateneos libertarios". Ajoblanco, núm. 23, Barcelona juny 1977, p. 8-10.

70 "Bajo el enunciado «Ball amb música viva» El «Ateneo Colón», reactivado por el "Sindicat Musical de Catalunya"”. .La Vanguardia, 6 de juny de 1980, p. 56. 
barri de Barcelona, ${ }^{71}$ de manera que es passa a trenta-nou cinemes que inclouen tots els barris de la ciutat, i es difon, a més, a vuitanta-quatre poblacions de Catalunya. ${ }^{72}$

Una altra iniciativa ben indicativa dels mitjans com a eines d'acció sociocultural progressiva i mitjans d'identificació i empoderament locals, és Ràdio Ponent (1981), una emissora privada i cooperativa ("una cooperativa de consum per als associats i una cooperativa de treball per als treballadors"), que neix de la petició que, a tal efecte, signen setze ajuntaments i associacions culturals del Pla d'Urgell el 1979. Segons un dels seus promotors, "Ràdio Ponent va ser una alenada d'aire fresc, una emissora oberta a diferents sensibilitats i projectes, compromesa i amb una clara adscripció nacional i un objectiu comarcal també clar: configurar culturalment el naixement del Pla d'Urgell. I l'objectiu es va aconseguir. No seré original a l'hora d'afirmar que el Pla d'Urgell no seria el mateix si no hagués existit Ràdio Ponent."73

Un altre marc incisiu en aquest sentit són les revistes locals (de poble, vila, barri): n'apareixen moltes entre les acaballes del Franquisme i els anys de la Transició. Fora interessant un estudi monogràfic (sòcio-històric) a nivell català sobre aquest tipus de premsa. I una altra esfera que caldria examinar, amb relació al binomi cultura popular-marcs locals, són les jornades de cultura/festa local que proliferen també durant aquest interval històric.

Volem, finalment, introduir uns breus apunts sobre la festa popular. Aquesta es converteix, més enllà de l'esbarjo, en un altre instrument bàsic de culturització i empoderament del lloc i de la seva identitat per part del comú de la gent. Pel que fa al període que ens concerneix, agafen força tres festes (o marcs festius) de clares connotacions populars i paganes: carnestoltes, Sant Joan i un conjunt de celebracions relacionades amb la

71 Quintà, Alfons. "Primera edición de “Noticiari de Barcelona”". El País, Barcelona 30 de juny de 1977.

72 González, Josep A. "Els noticiaris després del NO-DO” (http://www.bcn.cat/publicacions/ bmm/pdf_historic/06_BCN_Metropolis_Mediterrania/Noticiaris_Despres_ NODO.pdf )

73 Talarn, Joan. “Entrevista. Joan Solé Cercós. President de l'Ateneu Popular Plana d’Urgel”. Arts, № 34, (febrer de 2011): 5. Badia, Ramon. "Ràdio Ponent comença a emetre". Avui, Barcelona 8 de gener de 1982, p. 10. 
primavera. Respecte a aquestes darreres (les menys conegudes), destaquen les "festes de la primavera". Es tracta d'un tipus de festes que varien significativament d'un Iloc a un altre, i que tanmateix tenen en comú una difusió important en el decurs dels setantes i un caràcter (començant per la seva organització) popular. A Barcelona, per exemple, el 1978, se’n celebren a les Rambles organitzades per la seva associació de veïns, i al Poblenou amb el grup de titelles La Fanfarra i l'animador Joan Cots; o a també a Barcelona, el 1980, se celebren tot l'abril -emmarcant-s'hi Sant Jordiamb Comediants i el seu "Sol solet" com a manifestacions centrals, ${ }^{74}$ i també es fan al Clot i al Camp de l'Arpa organitzades, en aquest cas, per la Coordinadora d'Entitats d'aquests barris. ${ }^{75}$ Fora de Barcelona, veiem que se celebren a Girona des dels anys seixantes, durant tots els setantes

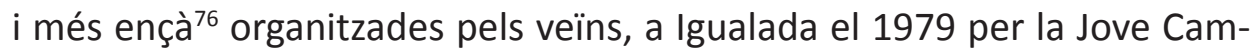
bra, a Sabadell -amb una primera edició el 1977- per la Jove Cambra i els esplais. I poden reportar-se també les Festes de la Primavera celebrades a la vall del Corb els primers vuitantes, empeltades d'un marcat caràcter alternatiu que és producte encara dels anys anteriors.

Tenim, d'altra banda, que a Granollers, organitzades per la delegació d'Òmnium, s'hi celebren les Festes Culturals de Primavera: el 1972 estan dedicades al mil·lenari de l'Abat Oliba i el 1974 a "El pessebre" de Pau Casals i a la figura d’aquest músic;" que a Arbúcies s’hi fa "La Prima-

74 J.L.C.: "Fiesta de Primavera en el Tinell. Para "Comediants" siguesaliendo el "sol, solet". La Vanguardia, Barcelona 20 d’abril de 1980, p. 54

75 "El próximo sábado tendrá lugar el "Gran Ball de Primavera» del Clot y Camp de l'Arpa. Su comienzo está previsto a las diez y media de la noche, en la Nau Gran del Clot, calle Edison, s.n. Organiza la Coordinadora d'Entitats del Clot i Camp de I'Arpa'. El precio de la entrada se ha fijado en 300 pesetas y actuarán la Orquestra Platería, Oriol Tramvia y Gato Pérez."(“Festes de Primavera» en el Clot y Camp de I'Arpa". La Vanguardia, Barcelona1 de maig de 1980, p. 54).

76 Per exemple, "Gerona: Comenzaron las Fiestas de Primavera". La Vanguardia, 28 d'abril de 1973 p. 39. "Amplia proyección de las "Festes de Primavera". La Vanguardia, Barcelona 22 d’abril de 1977, p. 27.“Comienzan las “Festes de la Primavera". La Vanguardia, Barcelona 22 d'abril de 1979, p. 27.

77 "Granollers: Conmemoración del milenario del abad Oliba". La Vanguardia, Barcelona 2 de maig de 1972, p. 35."Una extraordinaria audición de "El Pessebre", de Pau Casals, en Granollers". La Vanguardia, Barcelona 2 de juny de 1974, p. 57. 
vera Jove-75" que inclou un festival de cançó catalana; 78 i que l'Associació de Veïns de l'Esquerra de l'Eixample organitza, en el decurs d'uns quants anys, el "Concert de Primavera".

La reorientació democratitzadora de les festes majors és un altre aspecte rellevant de la democratització de la festa i de la cultura. És quelcom verificable a partir d'alguns ajuntaments del postfranquisme i de molts dels primers ajuntaments democràtics. La participació de les associacions de veïns, de grups de joves, de colles de cultura popular i tradicional, la descentralització urbana de la festa, l'ocupació emblemàtica del carrer, són alguns dels trets comuns d'aquest reenfocament de la festa major esdevingut en aquest període. Unes altres característiques són la recuperació i recreació d'elements de la tradició; la catalanització de la festa; i l'anul·lació d'expressions connotades de franquisme com concerts i cercaviles de bandes militars i "pasacalles" de "majorettes". És interessant, quant a aquest procés, la notícia "Nuevo enfoque a las Fiestas de la Merced" de l'agost de $1977^{79} \mathrm{i}$, respecte a Tarragona, l'article referit d’Alfred Fort.

\subsection{La cultura catalana. La seva promoció popular. La catalanitat popular}

En el curs del període que abordem, la promoció popular de la cultura catalana es configura com un altre dels àmbits amb caràcter autònom per bé que aquesta promoció és un tret prou (diversament) transversal en les cultures populars d'aquests anys a Catalunya.

Pel que fa a aquesta promoció popular(ista) de la cultura catalana, cal destacar un conjunt de festes de la cultura catalana amb caràcter emblemàtic. N'hi ha amb un caràcter anual i n'hi ha (per voluntat expressa dels promotors o per imperatiu de les circumstàncies) que se celebren un sol cop. La seva projecció global, el seu caràcter participatiu, la seva itinerància, en fan celebracions amb una contribució específica a la projecció popular de la cultura catalana, i al revestiment popular dels seus atributs.

78 "Arbucias: Festival "Primavera Jove-75". La Vanguardia, Barcelona 20 de juny de 1975, p. 61.

79 "Nuevo enfoque a las Fiestas de la Merced". La Vanguardia, Barcelona 7 d'agost de 1977, p. 19. 
Les més rellevants de les festes periòdiques parteixen de finals dels seixantes o del mateix 1970. Poden reportar-se les Festes Populars de Cultura Pompeu Fabra (1968-1993), reconegudes institucionalment el 1977, i que esdevenen una plataforma de promoció de joves escriptors: Àlvar Valls, Miquel de Palol, Josep Espunyes; les Festes de Maig de les Lletres Catalanes promogudes per Òmnium Cultural des del 1969, que tenen com a acte central el Iliurament del Premi d'Honor de les Lletres Catalanes, i que es revesteixen d'un caràcter entre popular i reivindicatiu fins el 1977; ${ }^{80}$ la festa de la Flama del Canigó que, per Sant Joan, d'ençà el 1966, es comença a repartir pel Principat i que l'any 1973 (quan és repartida en 125 pobles de Catalunya) arriba a la ciutat de València; la Festa de Renovació de la Flama de la Llengua celebrada des de l'any 1970 a Montserrat, on hi arriba, portada per excursionistes, un cop encesa a Prades de Conflent el diumenge anterior.

També hi ha festes puntuals que atenyen una projecció important. Una d'ineludible, atès l'especial relleu simbòlic i mític que aconsegueix, és el I Festival de Poesia Popular celebrat al Gran Price de Barcelona l'abril del 70. En l'esdeveniment, dedicat a Josep Carner que, vell i malalt torna puntualment de l'exili, hi participen els poetes catalans més destacats, i és presentat per Joan Colomines. D'altra banda, una altra festa remarcable és la "Trobada popular" de cloenda dels actes del Mil-lenari de Cuixà, celebrada el maig del 76 en aquesta vila, comptant amb funcions artístiques ben diverses (titelles, cinema, cançó, poesia...) i en què hi prenen part un grup molt nodrit d'artistes d'arreu dels Països Catalans. ${ }^{81}$ Les "50 Hores d'Art Català" de Balaguer del març del 75, que també funcionen com un aparador multiartístic, són un altre d'aquests esdeveniments de celebració i reivindicació popular de la cultura catalana.

80 "El martes, Premi d'Honor de les Lletres Catalanes. Les festes de maig de la cultura catalana". La Vanguardia, Barcelona, 4 de maig de 1978, p. 25.

81 Garcia, Xavier. "Veus joves festegen el mil·lenari. Teatre, poesia i cançons en un intens cap de setmana". Avui, 22 de juny de 1976, p. 1. Garcia-Soler, Jordi. "Al vent. Trobada popular a Cuixà". Avui, 19 de juny de 1976, p. 22. Garcia-Soler, Jordi. "Al vent". Avui, 20 de juny de 1976, p. 30. “"Trobada Popular" de conclusión del Milenario de Cuixá. Se celebrarán diversas actividades el sábado y domingo próximos." La Vanguardia, Barcelona, 17 de juny de 1976, p.32. 
D'una altra mena, unes iniciatives que cerquen també reivindicar i normalitzar la cultura catalana, i que malden, a tal fi, per la seva incidència popular, són la I Setmana de Cultura Catalana a la Universitat de Barcelona, i el Congrés de Cultura Catalana. Si el primer d'aquests esdeveniments se celebra entre el 14 i el 23 d'abril de 1975, el gener d'aquest mateix any hom aprova la celebració del Congrés, els treballs del qual es perllonguen fins el 1977. Són, l'un i l'altre, esdeveniments acadèmics i alhora populars tot i que les seves dimensions són molt diferents. Pel que fa a la Setmana de Cultura Catalana, celebrada a l'edifici històric de la Universitat de Barcelona, hi trobem, com esdevé habitual en les festes i mostres de cultura catalana d'aquests anys, una gran varietat d'expressions artístiques i temàtiques. S'hi fan, d'aquesta manera, exposicions d'art, conferències, taules rodones, recitals de cançó (J. Arnella i J. Dalmau, R. Subirachs...), teatre, un espectacle audiovisual, un muntatge a partir de l'obra de Salvat Papasseit, i danses tradicionals catalanes:

“Universitat. I Setmana de Cultura Catalana, dins una universitat en castellà

Entre dues dades històricament ben significades, el 14 d'abril, aniversari de la proclamació de la República, i el 23 d’abril, diada de Sant Jordi, del llibre i de la rosa, on a més de la tradició s'afegeixen tots els signes de la catalanitat, s'ha celebrat la I Setmana de Cultura Catalana, organitzada per la Universitat de Barcelona. Pera cada jornada han estat programats amb improvisada antelació un bon grapat d'activitats, taules rodones, conferències, recitals, representacions teatrals, etc., intentant desgranar a poc a poc, des del passat fms al present, la realitat que envolta els Països Catalans. ${ }^{82}$

Quant al Congrés de Cultura Catalana, cal tenir en compte dues condicions propiciatòries de base. Ens referim a la consciència popularista i

82 Cisquella, Georgina. "Universitat. I Setmana de Cultura Catalana, dins una universitat en castellà. Canigó, núm. 395, Barcelona, 3 de maig de 1975, p. 10. Vallet, Antoni F. "Taula rodona: La problemàtica del Ilibre català". Canigó, núm. 395, Barcelona, 3 de maig de 1975, p. 11-12. Broch, Àlex. "Tres representacions teatrals". Canigó, núm. 395, Barcelona, 3 de maig de 1975, p. 12-13. "Mañana se iniciará la I Semana de Cultura Catalana en la Universidad de Barcelona". La Vanguardia, Barcelona 13 d'abril de 1975, p. 30. 
catalanista dels anys en què se'n fa la proposta i se celebra, i fem referència a un conjunt de problemàtiques estructurals de la cultura catalana que es fan especialment patents a partir de l'any 1975. Respecte d'aquestes, es tracta, sumàriament, de la falta d'una definició global i integradora de la cultura catalana, de la manca d'un enquadrament que ordeni globalment aquesta cultura, i associat a això, una dissonància (explosiva) de models; de la dualització entre la cultura catalana (entre models culturals en català i identificats com a catalans) i una cultura recomposada cultura castellanòfona que esdevindrà parcialment (en els anys posteriors a la Transició sobretot) camp d'instrumentalització espanyolista; ${ }^{83}$ de l'especialització llibresca de la cultura catalana; de la propensió intel·lectual d'aquesta; dels dèficits pel que fa a l'estratificació i la popularització de la cultura catalana; de les mancances en la incorporació a la nova lògica hiperconsumista de la cultura (best-seller, llibre de butxaca), i dels dèficits en la moderna cultura audiovisual. ${ }^{84}$

La proposta del Congrés de Cultura Catalana -inicialment designat com a Congrés de Defensa de la Cultura Catalana- surt del Col·legi d’Advocats de Barcelona el gener de 1975. Els col-legis professionals tenen un paper destacat en els seus primers suports, i amb tot, el Congrés rep aviat l'adhesió d'un gran nombre d'entitats de tot tipus i d'arreu dels països de parla catalana, i de multitud de particulars. A meitat de 75, havent-s'hi barallat diversos plantejaments, queda fixada l'orientació estratègica del Congrés: una vocació propositiva més enllà dels posicionaments de denúncia; una definició àmplia de la cultura ${ }^{85}$ i una orientació clarament popular de l'esdeveniment que defugi l'elitisme (acadèmic); i els Països Catalans com a marc de la seva actuació. ${ }^{86}$

83 Quant a aquest aspecte, veu també Carod-Rovira, Josep L. La nova Catalunya. Barcelona: Edicions 62, 2003:

84 Molas, Joaquim. "La Cultura catalana i la seva estratificació..."

85 “(...) el Congreso de Cultura Catalana daráa la expresión cultura sumásamplíadefinición, incluyendo en ella todasaquellasmanifestaciones de lengua, derecho, pensamiento, conducta y formas de vida que caracterizannuestracondición individual y colectivacomo miembros de los Países Catalanes" (El Congreso de Cultura Catalana". La Vanguardia, 8 d'agost de 1975, p. 21.).

86 Quant al CCC, consultin, entre altres, aquestes referències: Duran, Lluís. El Congrés de Cultura Catalana i la transició política. Barcelona: Fundació Congrés de Cultura Catalana, 2013. Espar, Josep (2001). Catalunya sense límits 1963-1996. Barcelona: Edicions 62. 247 i ss. 
D'acord amb la diversitat dels seus objectes d'estudi, el CCC promou cinc campanyes de mobilització popular: entorn de la defensa del patrimoni natural, de la identificació del territori, de l'ús oficial del català, i de la revitalització dels valors populars i del folklore, i de les institucions. Cal destacar, així mateix, l'organització territorialitzada del Congrés (els secretariats locals, de barris...), i finalment la confecció d’un copiós llibre de conclusions:

"La Rambla del Poble Nou, el popular barrio barcelonés, fue testigo de una extraordinaria merienda para todo aquel que quisiera participar en ella. Consistía en el tradicional -y casi olvidado- "pa amb vi i sucre», una de las fórmulas gastronómicas más simples y suculentas. Una rebanada de pan, bienembebida en vino y espolvoreada de azúcar. El organizador del refrigerio había sido el secretari[ad]o local del Congrés de Cultura Catalana, con el objeto de llevar al nivel de la callesu alto postulado." ${ }^{87}$

També hi ha associacions i empreses que fan, aquests anys, un paper important de foment democràtic de la cultura catalana i d'impuls de les seves manifestacions més populars, com la cançó, la cultura popular i tradicional (les festes tradicionals)... D’acord amb el que és el període de màxima efervescència cultural i política, la major part d'aquestes associacions són fundades entorn de 1977. Repassem-ne succintament les principals.

Una entitat -aquesta mercantil- és Xarxa Cultural (1977), de què ja hem parlat. Aquesta neix “para que la cultura catalana deje de ser de peaje y pueda convertirse, de una vez por todas, en cultura normal, abierta a todos y de manera asequible a todos los bolsillos" 88 o, segons un dels seus impulsors, Josep M. Figueres, sorgeix perquè calia que "la cultura fos al carrer i a les places (...) una cultura no confosa amb la literatura, una cultura que afecti totes les activitats humanes amb un aspecte social i català..." ${ }^{89}$ L'empresa, ultra el nucli central de gestió, pretén dotar-se d'agents comercials, equips de treball locals, i subscriptors que, mercès a una quota, poden "beneficiar-se de

87 “"Pa amb vi i sucre" en el Poble Nou”. La Vanguardia, Barcelona 20 de setembre de 1977, portada.

88 "Una cultura de peaje". La Vanguardia, 1 d'abril de 1977, p. 23.

89 Figueres, Josep M. "Xarxa Cultural, nova empresa editorial". Avui, 8 de maig de 1977, p. 27. 
serveis que giren entorn del món cultural català entès com a edicions, discos, ceràmica, artesania popular, etc." També, en el marc de la seva actuació local, Xarxa es proposa recuperar oficis perduts..$^{90}$ L'entitat, val a dir, patrocina el prestigiós pemi d'assaig "Xarxa".

Una altra entitat de promoció popular de la cultura catalana, també del setanta-set, són els Consells Populars de Cultura Catalana, sorgits a finals d'aquest any, aprofitant l'estructura organitzativa generada a nivell local amb el CCC, i amb l'objectiu d'implementar les conclusions del Congrés:

"Consells populars de cultura catalana?

He assistit a la primera part de l'assemblea general de secretariats de barri del finit Congrés de Cultura Catalana. Tots volen continuar. La funció de popularització de la cultura és realment necessària ara i sempre. És una gran sort que als països catalans es desenrotllés un congrés de cultura que ha fet proliferar uns grups de divulgació de les seves tasques. Ara es troben implantats en molts barris, municipis i comarques de Catalunya Nord, del Principat, de les Illes Balears i Pitiüses i del País Valencià.

He sortit de la reunió abans que es decidís si d'ara endavant prendran el nom de Consells Populars de Cultura Catalana. S'han precisat llurs funcions davant l'Estat, els partits, les sindicats, les associacions de veïns. Omplen un buit social ben definit..."91

Els CPCC es constitueixen pròpiament a partir de 1978. S'organitzen per barris: Sant Antoni, Gràcia, Esquerra de l'Eixample...a Barcelona, i per localitats: Reus, Lleida, Viladecans...A Lleida, el Consell Popular de la Cultura Catalana de la ciutat organitza amb motiu de la Pasqua de 1979 la primera cantada de caramelles després de molts anys de relegament de la celebració. ${ }^{92}$ A Viladecans, en plena conurbació metropolitana de Barcelona, el Consell Popular de la Cultura Catalana s'hi constitueix el 1980. Amb una majoria de joves, té cura d'organitzar l'arribada de la Flama del Canigó per Sant Joan, i de recuperar el Carnestoltes, entre altres iniciatives:

90 Maluquer, Jordi. "Pre-política. Convocatòries abstractes". Avui, Barcelona 31 de març de 1977, p. 2.

91 Xirinacs, Lluís M. "Consells populars de cultura catalana?”. Avui, Barcelona 9 de desembre de 1977, p. 7.

92 "Vuelven las “Caramelles"” La Vanguardia, Barcelona 15 d’abril de 1979, p.22. 
"A Viladecans, si més no, els Consells Populars de Cultura Catalana es van constituir el gener de 1980 de manera assembleària (...). [Formen el Consell Popular de la Cultura Catalana de Viladecans] "gent amb ganes de mobilitzar culturalment la població, recuperar les festes i les tradicions que la dictadura ens volia fer oblidar, i integrar, mitjançant la festa popular, als nous catalans arribats d'arreu d'Espanya als anys 60, i que, per diverses raons, no se'ls havia deixat descobrir qui i què eren els Països Catalans i per què ens estimàvem la nostra terra." ${ }^{\prime 3}$

Els CPCC fan actes a favor de la normalització del català: restitució de noms catalans dels carrers, i a favor de la catalanització de l'esfera pública en general: promouen, així, la campanya "Ho volem en català" iniciada la tardor del 79.94 També prenen part en la campanya per als estatuts d'autonomia. ${ }^{95}$ El 1981 editen, amb la Fundació Jaume I, I'opuscle de Joan Fuster Per a una cultura catalana majoritària. Més a nivell anecdòtic, veiem que el setembre de 1981, el Consell d'Esplugues de Llobregat crida els seus conciutadans a boicotejar les sessions de cinema " $S$ " que es fan a l'Avenç d'aquesta ciutat per tal com desdiuen de la cultura. ${ }^{96}$

Ja ens hem parlat anteriorment de la Fundació Serveis de Cultura Popular, també de 1977. Si bé aquesta entitat edita materials i fa actuacions en el terreny específic de la cultura catalana, del seu foment popular, el gruix de la seva actuació, com hem raonat, el depassa.

D'altra banda, el 1977 es constitueix la Coordinadora d'Entitats per a la Defensa de les Nostres Festes, que té continuïtat una mica més tard en el Secretariat de Defensa de les Nostres Festes. Ambdues tenen com a objectiu la defensa de les festes tradicionals catalanes, i sorgeixen i es mobilitzen davant eventuals supressions d'algunes d'aquestes festes o

93 "Punt Viladecans de trobada. Els Consells Populars de Cultura" (puntviladecans. blogspot. com.es/2011/03/els-consells-populars-de-cultura.html)

94 "Decisión por cuentapropia".La Vanguardia, Barcelona 28 de juliol de 1978, p. 3. “Camapaña para normalización del catalán en al calle".La Vanguardia, Barcelona 30 d'octube de 1979, p. 27

95 Acte informatiu per la campanya dels estatuts d'autonomia dels Països Catalans.. Consells Populars de Cultura Catalana Esquerra de l'Eixample. [Gràfic].

96 "Esplugues de Llobregat. Protesta por un ciclo cine "S"". La Vanguardia, Barcelona 18 des setembre de 1981, p. 45). 
enfront de la seva anul·lació efectiva. Així, a la primavera de 1977, davant la possibilitat que se suprimeixi la festa del dilluns de Pasqua, la Coordinadora crida a festejar aquest dia i defensa les festes tradicionals catalanes -el dilluns de Pasqua, el dilluns de Pentecosta, Tots Sants i Sant Esteve"como fiestas enraizadas en el espíritu del pueblo catalán". Dos anys i mig més tard, el Secretariat, vinculat a Òmnium, que ja acull Tradicions i Costums, fa arribar la seva protesta al conseller de Treball de la Generalitat provisional per tal com s'han suprimit les festes de Tots Sants i Sant Esteve, i promou una "recogida de miles de firmas pidiendo sean respetadas nuestras fiestas", i afegeix que "(...) el pueblo catalán no pide ni quiere más fiestas, sólo las suyas, y muy a gusto prescindiría de las que no le son propias". Una dècada més tard, arran del RD del 3 de novembre de 1989, que publica el nou calendari oficial de l'Estat espanyol, que preveu "doce fiestas de alcance nacional" inamovibles, es reprèn, impulsada ara pel Secretariat Pro-Festes Catalanes, la campanya a favor de les festes tradicionals catalanes i d'un calendari propi. ${ }^{97}$

Ja hem parlat de les Festes de Maig d'Òmnium Cultural. Aquesta entitat promou altres iniciatives de projecció ciutadana i popular de la cultura catalana. Una d’aquestes és “Cultura en ruta" (1970), que consisteix en un bibliobús que viatja arreu dels Països Catalans per tal de donar a conèixer i vendre llibres i discos en català. I no pot obviar-se principalment la Delegació d'Ensenyament Català (1969), que el 1977, quan s'hi produeix un agut conflicte laboral, compta amb centenars de professors, i que promou, des del setanta-vuit, els premis escolars Baldiri Reixac de llengua i cultura catalanes.

Acabem de referir-nos al paper que esdeveniments festivo-culturals, entitats i associacions tenen en el realçament popular de la cultura catalana i en la regeneració d'una cultura popular pròpia. Més enllà d'aques-

97 "El lunes de Pascua, festivo no recuperable".La Vanguardia, Barcelona 3 d'abril de 1977, p. 1. "La supresión de la fiesta de Todos los Santos". La Vanguardia, BarceIona 18 d'octubre de 1979, p.1."Peticion para que se conserven las fiestascatalanas".La Vanguardia, Barcelona 30 d'octube de 1979, p. 27. Francés, Enrique. "Las cajas de ahorro y los bancoscerraránsus oficines el día de la fiesta de Reyes". La Vanguardia, Barcelona 31 de desembre de 1989, p. 62. "El cuento de nunca acabar. La regulación del calendario laboral catalán...".La Vanguardia, Barcelona 6 de gener de 1990 (“Economía y negocios”, p. 4). 
tes instàncies, hi tenen també, és clar, un paper fonamental un conjunt de manifestacions artístiques i culturals.

No hi ha dubte que la "Nova Cançó" -o la "Cançó" - es converteix en una de les expressions bàsiques de la cultura catalana dels seixantes $i$ setantes i, si atenem la seva projecció social, en la principal dins un marc heterogeni de recomposició i revitalització de la cultura popular catalana. La Nova Cançó, amb l'inicial article de Lluís Serrahima "Ens calen cançons d'ara" que advoca perquè els catalans cantin "cançons, però nostres i fetes ara (...) que tinguin una actualitat per a nosaltres", sorgeix amb la intencionalitat última de regenerar la cultura popular catalana, de suscitar una moderna cultura popular en català. Entre els seus factors sociogenètics, cal tenir present la voluntat de superació de la situació de replegament i tancament a què el Franquisme, durant les seves primeres dècades, ha abocat a la cultura catalana, la voluntat d'una certa estratificació-popularització de la cultura catalana a què acabem de referir-nos, ${ }^{98}$ i una nova consciència de poble emergida clarament als anys seixantes a la qual ens hem referit anteriorment.

La Nova Cançó -el seu corrent central, definit pels Setze Jutges i per altres intèrprets amb un estils que hi mantenen concomitàncies bàsiques- expressa amb registres populars un tipus de cultura elaborada també d'acord amb certs nivells d'intel·lectualització. El seus orígens en una (petita) burgesia urbana catalanista i l'ascendència que hi tenen els chansonniers francesos, poden contribuir a explicar aquesta característica que no és banal.

Val a dir, d'altra banda que la Nova Cançó es converteix, en la Catalunya dels seixanta i setanta del segle XX, en l'expressió paradigmàtica de la concurrència entre dos marcs sentimentals i ideològics bàsics: el catalanisme d'una banda, i el progressisme virat cap al marxisme de l'altra; o d'una altra manera, de la "cosmovisió" hegemònica en el catalanisme del moment: un catalanisme (marcadament) progressista o d'esquerres.

Les nombroses cròniques i crítiques de J. Garcia-Soler, Albert Mallofré o Àngel Casas poden ajudar-nos molt a una revisió sociològica del fet de la Cançó. Com és ben sabut, en la seva consolidació com a fenomen

98 Quant a aquestes qüestions, vegi's: Molas, Joaquim. “La cultura catalana i la seva estratificació..." 
massiu, hi tenen un paper decisiu, primer -cronològicament parlant-, Raimon, després Joan M. Serrat i Lluís Llach, i més tard La Trinca. Hi ha diversos aspectes que posen en relleu la popularitat d'aquesta expressió cultural. En primer lloc, la capacitat de convocatòria dels recitals i concerts, la profusió d'aquests i els importants contingents de discos venuts per part d’Edigsa (1961-1983) principalment. En segon terme, la força simbòlica i d'atracció dels seus principals certàmens: els recitals al Palau de la Música i a l'Olympia de Paris, i les Sis Hores de Cançó a Canet. En tercer lloc, la seva potent difusió territorial, de manera que, ben aviat i arreu de Catalunya (i també en els altres països de llengua catalana), se'n celebren recitals i festivals: així, entre els nombrosíssims casos adduïbles, veiem, per exemple, que a Altafulla, des de 1966, s’hi fa un Festival de la Nova Cançó Catalana, ${ }^{99}$ que a Bellver de Cerdanya el 1972 s'hi celebra la primera edició del festival "Cançó Jove" en què hi participen entre altres Joan Isaac i Els Sapastres, ${ }^{100}$ o més ençà, que a Bellpuig, el 1975 s'hi suspenen les Sis Hores de Cançó, ${ }^{101}$ que sí que poden celebrar-s'hi el 1976 i el 1977. I per acabar, la important proliferació de cantants i conjunts, una emergència que esdevé especialment vigorosa entre els últims anys de la Dictadura i els primers de la Transició, amb molts artistes que no arriben a consolidar-se o que no hi reïxen del tot.

Donat que aquest article se centra en expressions culturals emergents, noves, deixem de banda les manifestacions més tradicionals de la cultura catalana: la sardana, el ballet tradicional, el cant coral, orfeonístic, i això malgrat que aquestes, durant aquests anys, experimenten una important revitalització, i tenen un paper destacat en la resistència i la mobilització cívico-cultural a partir dels anys seixantes i durant els anys de

99 El 1972 se celebra a Altafulla el "V Festival de la Nova Cançó Catalana", que compta amb la presència dels grups «Aplec», "Som Nosaltres» y «Els Enjups». ("Altafulla, actividadesmusicales". La Vanguardia, 14 d'agost de 1970, p. 29.).

100 Bellcer, F. "Bellver de Cerdanya: Se celebró el II Festival de la "Cançó Jove»". La Vanguardia 16 d'agost de 1973, p. 46.

101 “El Festival de Bellpuig, no autorizado". Diario de Lérida, Lleida 1 d’agost de 1975, p.1. J.C. "Parcialitat simptomatica. Suprimides 6 hores de música, carta blanca a 24 hores de tenis". Diario de Lérida. Lleida 13 d'agost de 1975, p. 2. Benet, Carles. "Sobre la no celebración de les sis-hores de Cançó a Bellpuig". Diario de Lérida. Lleida 8 d'agost de 1975, p. $5 .$. 
la Transició. Tant és així, per exemple, que Joan Solé, un dels capdavanters del moviment sardanista a les Terres de Lleida en els anys de la Transició, afirma, quant a les primeres eleccions municipals, del 79 , la incidència que hi tenen, en la provisió de candidats, la Unió de Pagesos i el sardanisme: "En molts pobles [de "les terres de Ponent"], els caps de llista a les municipals eren els caps de colla de les respectives agrupacions sardanistes." 102

Cal fer avinent, d'altra banda, amb relació també a la cultura popular i tradicional, al que pot categoritzar-se com a tal, l'interès desvetllat durant la Transició per aspectes menys fixats d'aquesta cultura, menys institucionalitzats pel catalanisme, i per una geografia també en aquest ordre alternativa a la del folklore català consagrat i fixat a partir de la Renaixença. Aquest interès afecta manifestacions més connotades de ruralitat, de tradició rural: balls, castells, bestiari, instruments com la graIla... Emergeixen, així és, durant aquest període, un conjunt d'iniciatives d'estudi i foment de la cultura popular i tradicional orientades en bona mesura en aquest sentit i que tenen en la ciutat de Barcelona i la Catalunya nova uns pols bàsics de generativitat. Es tracta d'un fenomen que anticipa la recomposició fonamental del camp de la cultura popular i tradicional esdevingut a Catalunya a partir dels norantes del segle XX.

Les iniciatives al-ludides acostumen a adreçar-se a un doble objectiu: la cultura etnològica del passat, amb la voluntat d'estudiar-la, dotar-la d'un sentit actual, i promocionar-la; i l'estudi de les formes de vida del present. Poden fer-se avinents iniciatives com l'àmbit dedicat a l'antropologia i el folklore dins el Congrés de Cultura Catalana; l'edició de la revista GraIla (1977)103 i l'organització de cursos per a aprendre el toc d'aquest instrument tradicional a cura de la Societat Coral La Unió Vilanovina; I’aparició -els primers mesos de 1978- de l'Editorial Altafulla especialitzada en cultura popular tradicional; ${ }^{104}$ la fundació, el febrer d'aquest any, de I'Institut Català d'Antropologia, creat per tal d'estudiar les formes de vida

102 Talarn, Joan. "Entrevista. Joan Solé Cercós...": 4.

103 Gralla: circular de la Secció Folklòrica de la Societat Coral La Unió Vilanovina, núm. 1, Desembre 1976-Gener 1977

104 Permanyer, Luís. "Reediciones útiles". La Vanguardia, Barcelona 28 d’abril de 1978, p. 80. 
catalana -les tradicionals i les actuals- i de fer-ho al marge de la universitat perquè qualsevol que hi estigui interessat pugui participar-hi sense sentir-se exclòs o marginat; la reunió, una mica més tard, a Sant Boi, del Centre Recerca i Promoció de la Cultura Popular del Baix Llobregat que "considera como cultura popular toda manifestación actual o tradicional realizada con los medios inmediatos que proporciona el medio en el cuál vive quien la lleva a cabo"; ${ }^{105}$ I'aparició, a finals de la dècada, de les revistes Quaderns de I'ICA i Comentaris d'Antropologia Cultural; la fundació el 1980 a Reus de l'associació Carrutxa amb la finalitat de la recerca, difusió i dinamització de la cultura popular en el seu vessant tradicional i actual; les exposicions de cultura popular i tradicional com "La porta de l'estiu: Sant Joan" 106 del 1981, o l'èxit del Congrés de Cultura Tradicional i Popular celebrat el desembre de 1981 a Barcelona. ${ }^{107}$

Cal dir, així mateix, que en aquest context es recuperen o recreen aspectes de la tradició festiva. Són, així, aquests anys, els d'una sensible reactivació del fenomen casteller (la primera de les dues esdevingudes fins avui), i de recreació festiva com succeeix en el marc de la Mercè amb els correfocs, originats a partir de la tradició festiva del foc (dracs, diables).

\subsection{L'esfera alternativa i underground}

Una altra esfera fonamental en la recomposició de la cultura popular a la Catalunya dels setantes i anys anteriors, és el món de les expressions alternatives i sobretot el de les característicament underground. Aquestes darreres, com és apuntat per Maffi, conformen un camp magmàtic i proteic que es caracteritza per una forta generativitat i variabilitat, ${ }^{108}$ i que s'orienten, molt diversament, a la dissidència respecte als

105 "...Se pretende dar un sentido actual y activo a las costumbres, rituales y todo conocimiento popular, potenciando actividades de expresión artística, etnológica,de enseñanza, lenguaje rural, artesanía,etc. Se trata, en definitiva, de establecer el mayor numero de investigdores para el fomento y mejor conocimiento de la cultura popular en general. (J.P. “Promoción de la cultura popular en el Baix llobregat". La Vanguardia, Barcelona10 de març de 1978, p. 27).

106 Mañà, Joan et al: “Laporta de l'estiu: Sant Joan”. Barcelona: Caixa de Barcelona, 1981.

107 Llopart, Dolors i Joan Prat. "La cultura popular a Catalunya...": 152.

108 Maffi, Mario. La cultura underground. Bari: Laterza, 1972. 26-40. 
models artístics, culturals i socials institucionalitzats. Els seus camps principals d'expressió són la música i el teatre. Les expressions undeground suposen, en la Catalunya i l'Espanya del darrer Franquisme, les manifestacions més concordes amb la globalització de la cultura i dels estils de vida reforçada a partir de finals dels cinquantes arreu del món occidental, i representen, així mateix, el reflex més patent de les profundes contadiccions culturals i fenomenològiques que hi experimenta-críticamentsobretot la gent jove.

\subsubsection{La música}

\subsubsection{El folk i el folk-rock}

Pel que fa a la cançó folk catalana, podem establir dos moments principals: els últims anys 60 i els primers 70, i els darrers anys del Franquisme i els primers de la Transició. El primer correspon a l'eclosió del folk a Catalunya, amb un potent ascendent americà: Dylan, Baez, Seeger, i Peter, Paul and Mary. Són els anys del Festival de Folk (1968) i els anys, entre altres, de Fasterbo 3, Ara va de bo, Jaume Arnella, Ramon i M. Consol Casajoana, Dolors Lafitte, Jordi Fàbregas, Manel Lluís. I el segon moment coincideix amb una nova important emergència de grups i cantants: Uc (1973), Al Tall (1975), Esquirols (el primer disc és del 73), El Sac, i amb el debut de Marina Rossell (1974) i Celdoni Fonoll (1974) amb connexions amb l'esfera folk. I aquest segon moment també es caracteritza per un decantament del folk cap al rock com posen relleu, per exemple, els grups Coses i Rondalla de la costa, o com ho il·lustra la cançó "L'inadaptat" de Jaume Arnella inclosa en el disc Potser ja és ara l'hora (1976). D’altra banda, cap al final de la Transició, semblantment al que esdevé a la major part de les expressions emergents de la cultura popular dels seixantes i setantes, la cançó folk entra en declivi.

Parlem breument de les plataformes de promoció de la cançó folk. Respecte a aquestes, cal reportar les discogràfiques Als 4 Vents (19671982) -especialitzada en aquest tipus de cançó- i Edigsa i Concèntric (1964-1973); la promotora de cultura popular Enllaç a què ens hem referit; locals com La Cova del Drac en què actua Guillem d'Efak durant anys, el Teatre Capsa, o l'Aliança del Poble Nou en què s'hi celebra l'emblemàtic concert de l'abril del 75 amb Jaume Arnella, Xesco Boix, Falsterbo-3, la\&- 
Batiste, Manuel Josep, Jordi Pujol i el grup El Sac, o, on l'any següent s'hi celebra la I Mostra de Cançó Popular del País Valencià amb Els Pavesos entre altres grups; esdeveniments com les Sis Hores de Cançó en què hi actuen cantants i conjunts de folk; festivals de folk com els d'Arbúcies, ${ }^{109}$ Cardedeu ${ }^{110}$ o Capellades; "La Roda d'Espectacles als Barris" de Barcelona iniciada el 1977 i la Tamborinada promoguda per aquesta plataforma; el programa "La Caixa a les escoles"; la "Setmana de Música Viva" (1977-79) i el "Nadal al soterrani" (1977-78) a Barcelona; o les primeres edicions de Fira del Teatre de Tàrrega.

De la cançó folk, hom pot diferenciar-ne la folk-rock. Els seus primers exponents són els Tres Tambors, Pau Riba, Jaume Sisa i Música Dispersa. Els seus inicis es troben en el Grup de Folk. L'èxit del concert al Price de Barcelona de l'11 d'abril de 1970 amb Pau Riba com a atractiu principal, Música Dispersa (Sisa) i Om, i l'edició de Dioptria (1970-71) de Riba són fites importants en la consagració d'aquest corrent. Més endavant, s'afegeixen al folk-rock, entre altres conjunts, Coses (1972-1979), Rondalla de la costa, i Pep Laguarda. Els estils i les trajectòries d'aquests cantants i grups mostren, amb tot, diferències notables.

Pel que fa a les plataformes de promoció del folk-rock poden destacar-se els segells Als 4 vents, Concèntric, Zeleste, Edigsa i Movieplay; la sala Zeleste (1973); i diversos festivals. Respecte d'aquests, cal referir les Sis Hores de Cançó i sobretot el Canet Rock (1975-1978) promogut per la sala Zeleste, ${ }^{111}$ amb una forta presència de folk-rock en la seva primera edició, i amb Pau Riba que hi actua en totes les edicions i Sisa en les dues primeres. També pot reportar-se en aquest sentit el "Gran Festival de Folk-Rock" de Capellades de l'agost de 1975 amb Pi de la Serra, Sisa, Jaume Arnella, Pau Riba, Coses, Enric Sibina i Xesco Boix.

109 "Arbucias. Milenario nacimiento Abad-Obispo Oliva". La Vanguardia, Barcelona 22 de juny de 1971, p. 35..

110 La Vanguardia, Barcelona 15 d'agost de 1971, p. 27.

111 Gómez-Font, Álex. "Cataluña y el rock" en Mora, Kiko i Eduardo Viñuela (eds.). Rock around Spain. Historia, industria, escenas y medios de comunicación. Lleida: Universitat de Lleida, 2013. 131. 


\subsubsection{La música progressiva, l'“ona laietana” i altres manifestacions més experimentals.}

Respecte al rock progressiu, pot fer-se avinent que en són pioners a Catalunya i a l'Estat espanyol els grups Tapiman (1971-1972), Màquina! (1969-1972), la\&Batiste (1972-1976), Fusioon, Atila (1973-78), i Bueyes madereros. El primer festival de música progressiva que se celebra a l'Estat és el de Granollers del maig de 1971, en què, entre altres grups, actuen els catalans Màquina! i Fusioon (Manel Camp i Santi Arisa són membres d'aquest darrer), i per bé que l'any anterior s'havia celebrat el Festival Permanente de Música Progresiva al Salón Iris de Barcelona. ${ }^{112}$ L'any 1972 se celebren les 6 Hores de Música Progressiva de Sallent, un festival nodrit al complet per grups catalans: Om amb Toti Soler, Sisa i Música Dispersa, la\&Batiste, Bueyesmadereros, Slo-Blo (amb Gato Pérez) i Baf. ${ }^{113}$ Cal anotar, així mateix, que el novembre de 1973, també a Granollers i promogut semblantment per Joan Illa i el CIT d'aquesta ciutat, s'hi produeix l'actuació dels britànics King Crimson.

Els anys de màxima vitalitat pel que fa al rock progressiu i el laietà corresponen a l'interval 1974-1977. Es així, per exemple, que el 1974 es formen l'Orquestra Mirasol i l'Orquestra Plateria, que el 1975 apareixen Iceberg, Esqueixada Sniff, Barcelona Traction, Rondalla de la Costa, Miki Espuma, que és l'any d'eclosió definitiva de l’Elèctrica Dharma, i que el 1976 s'estrenen Música Urbana, Oriol Tramvia, Sècta Sònica, Blay Tritono, La tribu, etc.

Si ens preguntéssim per les plataformes d'actuació i promoció d'aquests corrents musicals, podríem adduir les següents: la sala Zeleste i la discogràfica del mateix nom; festivals com Onda Mediterránea ${ }^{114}$ i

112 Gómez-Font, Álex. "Cataluña y el rock...": 130. Aquest mateix mes a Granollers s’hi celebra la "1 Muestra de Arte Internacional de Homenaje a Joan Miró". Es una altra mostra de la inquietud de modernitat cultural alternativa promoguda a partir d'aquest moment a Granollers per part d'un grup de joves factors.

113 "Els Bueyes Madereros a les hores de música progressiva, a Sallent 1972" (http:// Iwsn.net/article/fotos-de-bueyes-madereros-a-les-sis-hores-de-musica-progresiva-de-sallent-de-1972)

114 Hi actuen l'Orquestra Mirasol, l'Elèctrica Dharma, Lone Star, Gato Pérez i el seu grup, el grup de Martí Soler, Toti Soler, Fusioon i Jordi Sabatés(“I Encuentro Experimental de "Onda Mediterránea". La Vangaurdia, Barcelona 31 d’octubre de 1974, p. 62.). 
sobretot el Canet Rock, el Grec (les seves primeres edicions) i la Setmana Música Viva; les Jornades Llibertàries de Barcelona del juliol de 1977; les revistes Disco express, Star, Rock Comix, etc.; i programes televisius com "Musical Express" conduït per Àngel Casas. ${ }^{115}$

A més de les expressions musicals ara apuntades, també es desenvolupa un rock més alternatiu i experimental del qual en són exponents grups com (Eix de) Baf, Perucho's, Tropopausa, Suck Electrònic, La Propiedad es un Robo o Los Psicópatas del Norte (aquests darrers es formen a les vigílies de les referides Jornades Llibertàries del juliol de 1977 en què actuen).

\subsubsection{El teatre}

Sense incórrer en l'esfera underground, el teatre independent forma part de l'escena teatral alternativa de la Catalunya del període que revisem. Quant a aquest tipus de teatre, decantat a la investigació i al risc, cal destacar el Grup A-71 (1973) impulsat i dirigit per Joan M. Gual (nét d’Adrià Gual), ${ }^{116}$ i que, entre el 73 i el 76, estrena, per exemple, tres obres de Pedrolo i dos de lonesco. D'altra banda, el mateix Gual i el seu grup vinculat a la Sala Gaudí participen activament en el Centenari d’Adrià Gual celebrat el 1973. També, en l'àmbit del teatre independent, poden destacar-se les companyies La Roda creada el 1975 i dirigida per Josep A. Codina, La Sínia (que a partir de muntatges del referit Codina sobre textos de Vidal i Alcover recorre Catalunya per portar el teatre a adolescents d'escoles i instituts), el Grup 69 i el Teatre de l'Escorpí.

Els Joglars, ben anteriors als grups referits, són un referent fundador del teatre independent i experimental a Catalunya i a l'Estat espanyol. Ja del període de la Transició, poden destacar-se M-7 Catalonia (1978) que integra l'espectador dins l'acció dramàtica, i el curt La festa dels bojos (1979) de Lluís Racionero, rodat a Rupit, que té una festa medieval com a punt de partida i que és interpretada per Els Joglars portant el teatre al cinema. ${ }^{117}$

L'àmbit principal del teatre underground és el teatre de carrer, d'animació, comunitari, i de titelles. Ens referim a un prolix ventall d'arts escè-

115 Gómez-Font, Álex. "Cataluña y el rock...": 132-133.

116 Gual, Joan M. "A-71 i el Teatre Regina". Assaig de teatre: revista de l'Associació d'Investigació i Experimentació Teatral, № 37, (2003): 103-110

117 "Con "La festa dels bojos"..La Vanguardia, Barcelona 6 de juny de 1979, p. 56. 
niques: putxinel-lis, ninots, pallassos, animació de cercavila, teatre de carrer, mim, jocs de mans... que experimenta una forta eclosió a cavall de la Dictadura i la Transició. Una característica bàsica n'és la recreació d'elements i sentits de la cultura popular tradicional. Ho fan patent, així, els noms dels grups: L’Estaquirot, Badabadoc, Ninots, Marduix, Naip, Trepadella. I ho posen de manifest els seus espectacles: així, per exemple, les creacions "Catacroc", "Plou i fa sol" i "Sol Solet" de Comediants, un grup, els muntatges del qual durant aquesta dècada i més enllà presenten concomitàncies clares amb el teatre de carrer i comunitari de Bread and Puppet. ${ }^{118}$ És indicatiu, d'altra banda, que l'any 1972, Als 4 Vents, el segell discogràfic folk, edita Les cançons de Putxinel-lis Claca d'aquest grup de titelles. Unes altres característiques d'aquests espectacles són una marcada vocació comunitària i una propensió al públic infantil i juvenil, semblantment al que s'esdevé en la cançó folk , i com sol ocórrer amb aquesta, d'acord amb una preocupació pedagògica i social progressista. El paper actiu conferit a l'espectador en fora un altre aspecte central, comú d'altra banda a tot el teatre independent i experimental d'aquests anys.

Fa més d'un any, el periodista Toni Vall en referir-se a la participació de Quico Palomar en els inicis de la Fura dels Baus, als setantes, diu: "Així, participa en la formació de La Fura dels Baus, una etapa inicial d'efervescència per festivals i cercaviles, un devessall d'espontaneïtat que aprofita al màxim. ${ }^{119}$

A aquest ambient i al seu moment històric també s’hi refereix Josep Giribet en evocar el substrat a partir del qual sorgeix la Fira de teatre al carrer de Tàrrega:

"A les acaballes de la dècada dels setanta, després del llarg període de repressions, es vivia una intensa efervescència creativa i de moviments reivindicatius. El teatre en va ser un dels exponents amb més impacte social. Molts grups joves, arrelats a la cultura popular, van optar per ocupar el carrer com a espai bàsic de representació i de trobada amb el públic, on l'espectador esdevé també protagonista."120

118 Maffi, Mario. "La cultura underground...": 390-394.

119 Vall, Toni. "Potser és ell l'últim romàntic". Ara, Barcelona 20 de juny de 2015.

120 Giribet, Josep. "Tots al carrer!..." 
Referim, a continuació, tres exemples d'afinitat entre teatre alternatiu, teatre de carrer i cultura popular tradicional. El primer és el festival infantil que el juliol de 1976, l'Assemblea d'Actors i Directors de Barcelona, que té cura del Teatre Lliure, organitza al bell mig de la plaça Catalunya de Barcelona:

"Numerosos niños y niñas animaron la plaza de Cataluña ayer por la tarde, en el transcurso del festival que para ellos organizó la"Assamblea d'actors i directors" dentro de su campaña de promoción popular "Teatre Grec 76". Los pequeños participaron en carreras de sacos, "trencar l'olla", ginkhamas y toda esta serie de juegos alegres e inofensivos que ya practicaban nuestros abuelos, pero que siempre son novedad. Los actores y directores animaron la fiesta con disfraces, cabezudos y reparto de juguetes, así como estimulando a los niños y niñas a realizar dibujos con tiza, alusivos todos al teatro. Una fiesta simpática y muy concurrida que dió una nota de color en la popular plaza de Cataluña..." ${ }^{121}$

El segon és el tipus de cercaviles previstes per a les festes de la Mercè del 79:

“(...) Los pasacalles constituirán sin duda alguna, la manifestación callejera más vistosa, sonora y alegre de estas Fiestas de la Merced. Durante tres días y partiendo de barrios distintos recorrerán la ciudad para concentrarse finalmente en su parte más céntrica.

(...) Cada uno de estos «cercaviles» estará acompañado en su respectivo recorrido por grupos de gigantes, músicos, comediantes y demás colectivos de artistas. Concretamente, para este dia está prevista la actuación de los siguientes grupos: Titelles Naip, Col.lectiu d’Animació, Drac, Planxet i Sia y los gigantes del Pi, Sant Roc y Sant Medir...."122

I el tercer són les primeres edicions de la Fira del Teatre de Tàrrega, que beuen de la mobilització popular i cultural dels anys previs. Així, pel que fa a la primera edició, de 1981, dita "Fira de Teatre,Trifulgues i XimXim al Carrer", durant tres dies i en diversos carrers i places de la ciutat, s'hi representen espectacles de la cultura popular tradicional (el Tararot

121 "Festival infantil a la Plaça Catalunya". La Vanguardia, 30 de juliol de 1976, p. 23. "Gran Festival infantil a la Plaça Catalunya”. L’Avui, Barcelona 28 de juliol de 1976, p. 22.

122 "La ciudad en fiestas". La Vanguardia, Barcelona 21 de setembre de 1979, p. 13. 
de Sitges, els Grallers de Cervera, els Trabucaires de Solsona, les Bastoneres de Sant Esteve de Palautordera, l'Esbart Albada de Tàrrega, acordionistes,...); i se'n representen d'inspiració tradicional com són força de les actuacions de teatre de carrer (la de Comediants, "Sol, solet", que inaugura la Fira; la de la Viu Viu Teatre, Pa de Ral, Curial Teatre...), actuacions de titelles (Marduix), de grups d'animació infantil, de folk (Enric d’Armengol, l'Orquestrina Galana...), etc.

Quant a les plataformes de foment d'aquest tipus de teatre-de carrer, comunitari, de titelles, d'animació festiva- poden referir-se les promotores Enllaç i Rialles; els festivals internacionals de titelles de Barcelona -1973, 1974, 1975 i 1977- organitzats per l'Institut del Teatre; les primeres edicions del Grec; la "Roda d'Espectacles als Barris"; el programa "La Caixa a les escoles"; la "Setmana de Música Viva" i el "Nadal al soterrani" a Barcelona; i la Fira del Teatre al Carrer a Tàrrega, sobretot les seves primeres edicions.

Afí al teatre independent, tenim el que Maffi anomena "teatre de recerca"; un tipus de teatre regit per la recerca de noves possibilitats expressives i per atorgar una dimensió enigmàtica, mística i metafísica a les obres. ${ }^{123}$ Una obra que podria relacionar-se amb aquesta modalitat teatral és Mori el merma de La Claca. Començada a preparar a finals de 1976 i estrenada a Palma el març de 1978, és una farsa complexa, que concilia ninots i màscares (manllevats de les obres que Joan Miró efectuà sobre el personatge d'Ubú rei d'Alfred Jarry), ball, acrobàcia... ${ }^{124}$

El teatre de guerrilla és un altre tipus d'expressió teatral underground. Es caracteritza per tractar-se d'intervencions directes, immediates, massives i simbòliques, per adreçar-se a un públic predisposat, i per actuar incisivament amb relació "il nocciolo d'un problema o d'un sentimento": "Il teatro di guerriglia è azione simbolica. Si chiama "di guerriglia" perché alcune sue strutture sono state prese dalla guerra di guerriglia: simplicità de tattiche, mobilità, piccoli gruppi, pressione nei punti più deboli, sorpresa. (....). Realizzare un'azione o immagine fulminea che colga il nocciolo d'un problema o d'un sentimento, far capire alla gente dove vive, ed in che situazione...." ${ }^{125}$

123 Maffi, Mario. "La cultura underground...": 388-389

124 Permanyer, Lluís. "Vuelta de Miró al teatro". La Vanguardia, Barcelona 15 de març de 1978, p. 70.

125 Maffi, Mario. "La cultura underground...": 406. 
Un exponent de teatre de guerrilla és el muntatge "La mare dels ous" que el grup artístic 2 quarts de deu (el poeta Joan Barceló n'és un integrant) representa en les 50 Hores d'Art Català a Balaguer el març de 1975 i que és assaltat per un grup. ${ }^{126}$

Els happenings i sobretot els tipus d'aquestes accions teatrals més enfrontades al poder, tenen similituds amb el teatre de guerrilla. En parlar dels happennigs (en termes d'actuació i estudi) a la Catalunya de l'etapa que ens ocupa, hem de fer-ho dels happennigs que es celebren a Granollers: així, l'escenificació el 1973 -quan la preparació del projecte "Art a Granollers"- del Sant Sopar a la plaça d'en Perpinyà;"127 el happening "Alta Mongolia" que, amb la presència de Salvador Dalí, se celebra el 19 d'agost de 1974 a la Porxada de la ciutat, i que és tanmateix un resultat devaluat respecte al projecte inicial "Viaje a la Alta Mongolia" que havia de ser protagonitzat per Dalí acompanyat de mil persones vestides de xineses;" ${ }^{128}$ el I Congrés Internacional de Happening celebrat el març de 1976, de què n'és promotor, com l'esdeveniment anterior, Joan Illa; ${ }^{129}$ i el Ilibre Happening de happenings y todo es happening (1979) d'aquest jove activista granollerí i que té com a objecte la divulgació del congrés de tres anys abans.

De l'actualitat del happening durant aquest moment històric n'és il.lustrativa també aquesta referència de Ferran Monegal a l'actuació del grup teatral Nyaca a la Rambla de Canaletes el juliol de 1974:

"El grupo de teatro una vez dentro del corro, se despojó de los sacos y a modo da pulpo fue ejecutando amórficas pantomimas, leves esbozos tomados del mimo, mirando al público con aspecto de terror y miedo. En

126 Guasch, Jordi. "Balaguer en las "50 Hores d'Art Català". Diario de Lérida, 2 d'abril de 1975 , p. 5.

127 Serra, Glòria. "Homenaje al hombre, de Paco Merino". Lauro: revista del Museu de Granollers, № 30, (2009): 104-106.

128 "Salvador Dalí Happening Granollers, 1974" (https://www.youtube.com/ watch?v= opGCK5DGFHc). "Granollers: "HAPPENING" CHINO DE SALVADOR DALÍ El resultado fue menos espectacular de lo esperado". La Vanguardia, Barcelona 20 d'agost de 1974, p. 30. Cifra. "Granollers: Salvador Dalí necesita mil «chinos» para un «happening»". La Vanguardia, Barcelona 11 d'agost de 1974, p.31.

129 "Granollers: cuando la vida puede ser arte y el arte ser vida. Se celebró el «1 Congreso Internacional de Happenings". La Vanguardia, Barcelona 30 de març de 1976, p.36. 
seguida los jóvenes, que se apiñaban en e! centro, fueronacercándose a los improvisados espectadores hastatocarles con susmanos para asíestablecer lo que más tarde me contarían como «comunicación á través de sensualidades»." 130

Val a dir, finalment, que la tradició de happenings que, per exemple, se celebren a la comarca d'Osona entre finals dels setantes i entrats els vuitantes, no poden dissociar-se de l'esperit de la Transició i dels anys previs. ${ }^{131}$

Finalment, un altre tipus de teatre underground és de debat, informació i denúncia. Aquest es caracteritza per versar sobre temes pròxims al públic, provocar-hi una resposta i crear subsegüentment una situació crítica capaç d'influir en la realitat i transformar-la. ${ }^{132}$ Amb aquesta modalitat pot vincular-s'hi les obres la peça teatral de M. Aurèlia Capmany i Xavier Romeu, Peguntes i respostes sobre la vida i la mort de Francesc Layret, advocat dels obrers de Catalunya (1970), i La Setmana Tràgica (1975) de Lluís Pasqual i Guillem J. Graells. En aquesta, estrenada el gener de 1975 a l'Aliança del Poblenou, "el públic era situat al mig mentre que l'acció i les estructures de l'escenari ens envoltaven per tots els costats..."133

Encara en el món escènic, els espectacles de Christa Leem també convergeixen a la revolució escènica dels anys setantes. Els seus espectacles suposen, des dels inicis de la Transició, una renovació i conversió artística del music hall. Esdevenen emblemàtiques les seves col·laboracions amb Joan Brossa.

\subsubsection{Altres expressions artístiques i culturals underground}

I és clar que la contracultura no pot entendre's sense el còmic underground. Revistes com El Rrollo enmascarado, Star, Rock Comix, El

130 Monegal, Fernando. "Teatro en la calle". La Vanguardia, Barcelona 31 de juliol de 1974, p. 27.

131 Coromina, Toni. Els happenings de la «transició» inacabada. Crònica de les facècies dels "contraculturals" vigatans (1979-1985). Nació Digital, 2 de maig de 2014.

132 Maffi, Mario. "La cultura underground...": 404-405.

133 Massip, Francesc. "Dramaturgs i teatrers de la generació dels 70: els ous d’or de la gallina?". La generació dels setanta: 25 anys. Barcelona: Associació d'Escriptors en Llengua Catalana, 1996. 72. Rosselló, Ramon M. "Sobre el realisme històric i el teatre document". Caplletra, № 28, (Primavera 2000): 149. 
Víbora, Contactos (de diferents moments dels setantes i de la primeria dels vuitantes) reporten periòdicament còmics inscrits en aquesta concepció. Dibuixants com Nazario, Mariscal, Max o Gallardo destaquen en aquest vessant.

Aquests anys també es manifesta una pintura contracultural. Heu-ne ací una expressió representativa: les obres del grup d'Art pel Poble. Aquest, el 1976, edita Desperta ferro!, un opuscle que conté textos i pintures que transporten el lector/visor a uns mons d'onirisme, tradició popular, ocultisme. Amb textos de Joan Barceló i fotografies de Julià Peiró, el llibre inclou presentacions, textos i il-lustracions dels membres del Grup: Vitriol (Martí Teixidó), Odina Martí, Xavier Vilallonga, Joan Barceló, Emili Flotats i A. Mamuyac Roca. ${ }^{134}$

D'altra banda, també cal contemplar la literatura contracultural, que és sobretot poesia contracultural. Recentment, David Castillo i Marc Valls han editat una compilació de poetes contraculturals barcelonins, nascuts entre el 1947 i el 1967, i morts tanmateix prematurament. ${ }^{135} \mathrm{En}$ un terreny concret, el poemari de Joan Barceló Diables d'escuma (premi Vicent Andrés Estellés de poesia de 1979) és altament identificatiu de la poesia contracultural d'aquest moment.

I també es produeix una festa contracultural. Ja ens hem referit a les Jornades Llibertàries de 1977. L'“Orgia artística” celebrada al Poblenou els anys 1987 i 1988, amb 12 hores seguides d'activitats, tot i excedir els anys de la Transició, obeeix a una concepció alternativa i transgressora de festa que beu encara de les concepcions de la dècada anterior:

“(...) el dia 24 de gener, de les 10 del matí a les 10 de la nit tindrà lloc la 2a Orgia artística. Durant 12 hores es possibilita la creació a partir de les més diferents experiències dins de tots els camps de la producció cultural (pintura, música, teatre, còmic, fotografia, vídeo, gastronomia i més...."136

134 Grup d’Art Pel Poble. Desperta Ferro!. Barcelona: el Grup, 1976.

135 Castillo, David i Marc Valls (comp.). Poesia, contracultura, Barcelona. Barcelona: Ajuntament de Barcelona, 2016.

136 "El último viaje a Icaria" (https://elultimoviajeaicaria.files.wordpress.com/2012/06/ orgiaartflordemaig.jpg 


\section{Conclusions}

Semblantment al que s'esdevé a les societats occidentals, a Catalunya dels setanta del s. XX s'hi produeix globalment una intensa recomposició i galvanització de la cultura popular. S'hi configura, així, un univers cultural marcadament heterogeni i emergent, amb vocació de públics amplis, "democràtics, "populars", i s'hi manifesta alhora, amb una relació fluïda amb aquesta esfera, una cultura underground de vocació alternativa. Es tracta, en conjunt, d'un món que, especialment pel que fa alguns dels seus camps, experimenta un vigorós dinamisme expressiu, i es tracta, sigui com sigui, d'un univers dotat d'una viva capacitat organitzativa i de mobilització. Les expressions d'aquesta esfera són d'una extrema heterogeneïtat quant a arts, gèneres, registres o marcs estètics.

Tot i l'extrema diversitat d'aquest univers, s'hi conformen tres àmbits bàsics d'orientació i producció: l'acció sociocultural progressista (la recuperació i promoció d'una cultura progressista, i amb relació amb això, la democratització de la cultura -entesa com a coneixement lato senso-, el fer-la accessible a sectors amb dèficits i dificultats de culturització i a públics amplis en general); la promoció popular de la cultura catalana; i la cultura alternativa i d'avantguarda i la contracultura.

Més enllà, pel que fa a aquest univers cultural, poden inferir-s'hi un conjunt de trets que s'hi manifesten ben transversalment. Un d'aquests és el protagonisme juvenil; un altre, la concepció de l'art o la cultura com a eines d'afirmació i empoderament populars, i de transformació social; una altre, l'autoorganització o l'autogestió per part de la mateixa gent destinatària o dels mateixos artistes; una altra característica és la concepció de la cultura com a instrument d'identificació, cohesió i empoderament local (de barri, vila, poble); i finalment, uns altres trets àmpliament rellevants de les cultures populars d'aquest període són la catalanitat per bé que concebuda molt diversament, la festa i la (para)teatralitat, i les concepcions de l'art i la cultura i al servei de la transformació social.

Quant a la promoció de la cultura popular durant aquest període, cal destacar també el paper que hi tenen moviments molt diversos l'orientació i l'activitat dels quals els posiciona en contra de la Dictadura i a favor d'una intensa democratització social i del restabliment nacional de Cata- 
lunya. En són exponents el moviment veïnal, sindical, de renovació pedagògica, de renovació eclesial, sardanista, "cineclubista", etc.

Respecte a les dinàmiques temporals d'aquesta transformació cultural, cal remarcar que la seva màxima intensitat correspon globalment al període comprès entre els darrers anys del Franquisme i els primers de la Transició, i sobretot a aquests darrers.

D'altra banda, quant als factors sociogenètics d'aquesta vasta transformació, cal adduir primer que tot les fonamentals contradiccions culturals i fenomenològiques que afecten les societats industrials avançades (manllevem la categoria de Marcuse) a partir meitat segle XX; de manera que alhora que s'hi produeix una intensificació del consum(isme), una complexificació de la societat, uns increments en la percepció oberta o panoràmica del món, i de manera més essencial, una densificació, facilitació i sensualització de la informació i l'estimulació social, s’hi mantenen (contradictòriament) unes estructures culturals, socials i polítiques percebudes i avaluades com a vitalment constrictives o repressives per part sobretot dels joves, que són els més sol-licitats pel consumisme i els que també, per imperatius psicoevolutius, més s'adonen dels canvis socials; i en tant que, de tot plegat, en resulten una agudització social (entre els joves especialment) de l'anomia (dels problemes de plausibilitat del jo amb relació al món), uns imperatius al desbordament de les restriccions culturals i polítiques, i una complexificació i recomposició de les identitats socials. Quant a aquesta darrera qüestió, és imprescindible destacar la consagració de la joventut com un nou estadi evolutiu privilegiat, àdhuc (com formulen Joseph i Margaret Rowntree), com una nova classe, i més enllà com un nou i poderós valor social, l'emergència del "poble" com una renovada i potent identitat, i la incipient (malgrat que larvada encara) crisi de la plausibilitat fenomenològica -o com a marc identificador- de la nació moderna.

Amb relació a aquesta fenomenologia, a la contradicció essencial que enclou, cal afegir-hi, és clar, factors sociohistòrics de la Catalunya i l'Espanya dels seixanta i setanta; factors que tensen i extremitzen aquesta contradicció. En primer Iloc, el Franquisme, la seva naturalesa dictatorial; en segon terme, la dinàmica social i política esdevinguda entre el 1969/1970 quan s'aguditza la crisi del règim franquista i el 1977 quan es 
produeix la primera consolidació de la Transició, una dinàmica caracteritzada d'una banda per incisives expectatives de canvi i de l'altra per actuacions de signe involucionista o insatisfactori en termes de ruptura amb el llegat franquista; tercerament, la crisi econòmica i social derivada de la crisi del petroli del 73 que a l'Estat espanyol, quan els primers anys de la Transició, es concreta en un fort increment de la inflació i en un significatiu increment de l'atur; i finalment, el caràcter més obert i dinàmic de la societat barcelonina i catalana.

Del revisat en aquest estudi, s'infereix també que el Franquisme provoca un endarreriment en la recepció de corrents artístics i culturals. Això esdevé palès sobretot en l'underground, el món per excel·lència que s'inspira en models forans. La seva cronologia i els termes de la seva recepció ho posen en relleu. D'altra banda, el Franquisme i el fet nacional català fan que, a Catalunya, el procés d'eclosió i recomposició de la cultura popular que es produeix arreu del món occidental durant els seixantes i setantes, tingui com a àmbits amb un pes propi molt important l'acció sociocultural progressista i la promoció popular de la cultura catalana.

Acabada la Transició, el futur d'algunes les expressions principals de la cultura popular dels setanta, és ben divers. Observem, d'una banda, una integració i promoció institucional i un foment associatiu d'un conjunt d'expressions de la cultura tradicional: balls, diables i correfocs, bestiari, castells o instruments com la gralla. Es produeix també una promoció institucional i una professionalització de grups teatrals procedents del teatre alternatiu i underground. Es un procés correlatiu a un decantament progressiu cap a propostes més hàbils comercialment. Es constata, d'altra banda, un declivi de l'embranzida en iniciatives de democratització cultural i progressista: ateneus (populars), revistes locals, jornades de cultura popular, etc.; i un decaïment i substitució d'iniciatives de promoció popular i transversal de la cultura catalana com els CPCC i d'esdeveniments d'aquesta naturalesa. La institucionalització de la Generalitat de Catalunya i d'un nou programa institucional en general, resulta decisiu en aquestes circumstàncies. D’altra banda, l’aparició de la Crida a la Solidaritat (1981) i dels GDL (1982) suposa reprendre la lluita per la llengua catalana en un context diferent: el de reacció al Manifiesto de los 2300 i a la LOAPA, i de radicalització de l'independentisme. I es produeix una desac- 
tivació (induïda en bona mesura) de la Nova Cançó; i en una esfera ben altra, un declivi del rock i la música alternativa en general dels setanta (folk-rock, rock progressiu, ona "laietana").

\section{BIBLIOGRAFIA}

Aisa, Ferran. "Els ateneus, una alternativa cultural fallida". Rafael Aracil, Amadeu Mayayo i Antoni Segura (eds.). Memòria de la Transició a Espanya i a Catalunya. Volum VI-VII. Barcelona: Centre d'Història Internacional, 2006, 181-208. Imprès.

Álbum Star: sólo para adultos. Barcelona: Promociones Editoriales. Impreso.

Bakhtin, Mikhail. L'oeuvre de François Rabelais et la culture populaire au Moyen Âge et sous la Renaissance. Paris: Ed. Gallimard, 1970. Imprimé.

Barnils, Ramon. La contracultura en acción: Ajoblanco. Bellaterra: UAB. Tesi de llicenciatura, 1979.

Berger, P. Luckmann, T. La construcció social de la realitat. Barcelona: Herder, 1988. Imprès.

Brossa, Joan, Fàbregas, Xavier, Nadal, Eugeni. La Fira del teatre trifulgues xim xim al carrer de Tárrega. Barcelona: Generalitat de Catalunya, 1982. Imprès.

Burke, Peter. Popular Culture in Early Modern Europe. London: Temple Smith Ed, 1978. Print.

Chambers, Ian. Popular culture: the metropolitan experience. New York: Methuen1986. Print.

Cuadrado, Jesús. Atlas español de la cultura popular: De la historieta y su uso 1873-2000. Madrid: Ediciones Sinsentido, 2000. Impreso.

Cuesta Gómez, Miguel. "El moviment veïnal al Bracelonès Nord (19541987)". Franquisme \& Transició, 3 (2015): 121-156. Imprès.

Eco, Humberto. Seis paseos por los bosques narrativos. Barcelona: Lumen, 1990. Impreso.

Eco, Umberto. Los límites de la interpretación. Barcelona: Lumen, 1992. Impreso.

Foguet, Francesc, Santamaria, Núria (eds.). La revolució teatral dels setanta: II Jornades de debat sobre el repertori teatral català. Bellaterra: Universitat Autònoma de Barcelona, 2010. Imprès. 
García Canclini. La cultura popular: de la épica al simulacro. Barcelona: MACBA, 2007. Impreso.

Ginzburg, C. Il formaggio e i vermi: il cosmo di un mugnaio del' 500. Torino: G. Einaudi Ed., 1977. Stampato.

Gramsci, A. Quaderni del carcere. Torino: G. Einaudi Ed., 1975. Stampato. Juliano, Dolores. La cultura popular. Barcelona: Antrophos, 1986. Impreso. Lee Harrington, C., Bielby, Denise D. (Eds.) Popular culture: production and consumption. Malden: Blackwell, 2005. Print.

Laborda, Xavier. Comunicació institucional i literatura de paperera. València: Edicions 3 i 4, 2001. Imprès.

Lakoff, Georges. Women, fire, and dangeorus thinks: what categories reveal about the mind. Chicago: University of Chicago Press, 1987. Print.

Lakoff, Georges. No pensis en l'elefant!: Ilenguatge i debat polític. BarceIona: Viena Ed., 2008. Imprès.

Lladonosa, Manel. "La Transició i els seus contexts". IXè Congrés de Convivència Cívica a la Ciutat "La Transició Democràtica a Lleida". Lleida 26-28 de març de 2015. Imprès.

Llopart, Dolors, Prats, Llorenç i Prats, Joan. La Cultura popular a Catalunya: estudiosos i institucions, 1853-1981. Barcelona: Fundació de Serveis de Cultura Popular, 1982. Imprès.

Llopart, Dolors, Prats, Llorenç i Prats, Joan. La Cultura popular a debat. Barcelona: Fundació de Serveis de Cultura Popular, 1985. Imprès.

Massana Soler, Herbert. "Grups d'animació". Festes.org.

Molinero, C., Ysàs, P. Construint la ciutat democràtica: el moviment veïnal durant el tardofranquisme i la transició. Barcelona: Ed. Icària, 2010. Imprès.

Orensanz, Aurelio. Contracultura y revolución. Madrid: Castellote, 1976. Impreso.

Reixach, Modest (coord.). Calendari de festes de Catalunya, Andorra i la Franja. Barcelona: Fundació de Serveis de Cultura Popular, 1989. Imprès.

Racionero, Lluís. Filosofías del underground. Barcelona: Anagrama, 1977. Impreso.

Salvat, Ricard. "El teatre de la Transició" dins: Rafael Aracil, Amadeu Mayayo i Antoni Segura (eds.). Memòria de la Transició a Espanya i a Catalunya. Volum VI-VII. Barcelona: Centre d'Història Internacional, 2006, 209-220. Imprès. 
Sanchís, Jordi. Contracultura y término popular. Barcelona: Facultat de Filosofia de la UB, 1978. Impreso.

Schutz A. The phenomenology of the social world. Evanston, IL: Northwestern University Press, 1967. Print.

“Una cultura de peaje". La Vanguardia, Barcelona 1 d'abril de 1977, p. 23. Impreso.

\title{
Joaquim Capdevila i Capdevila
}

\section{POPULAR CULTURE IN 1970s CATALONIA. A DRAFT STUDY}

\begin{abstract}
Summary
During the 1970s Catalonia witnessed an intense galvanisation and restructuring of popular culture. In fact, a new framework of popular culture was emerging. It was inextricably linked to the new concepts of culture, art, creativity, entertainment, as well as to the extremely popular rallies. The period of greatest vitality of this new (or intensely renovated) popular culture coincided with the final years of the Francoist regime and the early years of the Transition in particular. We should also point out that these years were marked by an intense galvanisation of public life with regard also to political activity, trade unions, community associations, etc. On the other hand, we must bear in mind that this popular culture was extremely diverse. Nevertheless, we can distinguish between three basic spheres: progressive sociocultural action, popular promotion of Catalan culture, and underground culture.
\end{abstract}

Keywords: Catalonia, popular culture, revitalisation and renovation of popular culture, the seventies, late Francoism, Transition to democracy, Catalan culture, progressive cultural action, underground culture. 